\title{
Contribuciones al conocimiento de la edad de los cuerpos ígneos plutónicos, hipoabisales y volcanoclásticos aflorantes en el área del municipio de Pailitas (Cesar, Colombia)
}

\author{
William David Avellaneda-Cáceres ${ }^{1,2 *}$; Camilo Alberto Anaya-Ariass, ${ }^{1,2}$ Andrea Carolina Ayala, ${ }^{1,2}$; \\ Luis Carlos Mantilla-Figueroa'; ${ }^{1}$ Rocío Bernal-Olaya ${ }^{1}$; Francisco Velandia ${ }^{1}$
}

doi: https://doi.org/10.18273/revbol.v42n2-2020006@ @

Forma de citar: Avellaneda-Cáceres, W.D.; Anaya-Arias, C.A.; Ayala, A.C.; Mantilla-Figueroa, L.C.; BernalOlaya, R.; Velandia, F. (2020). Contribuciones al conocimiento de la edad de los cuerpos ígneos plutónicos, hipoabisales y volcanoclásticos aflorantes en el área del municipio de Pailitas (Cesar, Colombia). Boletín de Geología, 42(2), 105-127. doi: 10.18273/revbol.v42n2-2020006.

\section{Resumen}

En el sector del municipio de Pailitas (departamento del Cesar), localizado entre las cordilleras Oriental y Central de Colombia, afloran mayoritariamente rocas Precámbricas (tanto de alto como de bajo grado de metamorfismo) y Mesozoicas (plutónicas, hipoabisales, volcanoclásticas, volcanosedimentarias y sedimentarias continentales), estas últimas agrupadas dentro de la denominada Formación Noreán.

La relativa amplia distribución espacial de las rocas de esta unidad, las relaciones entre sus diferentes litologías, las edades de cristalización de sus cuerpos ígneos plutónicos e hipoabisales (edades U-Pb en circones de

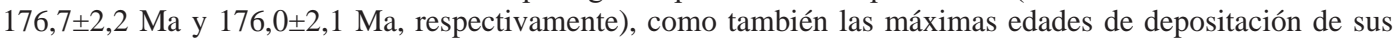
rocas volcanosedimentarias (con picos de edades U-Pb en circones detríticos alrededor de $190 \mathrm{Ma}$ ), sugieren que esta unidad se formó en un ambiente tectónico extensivo, el cual permitió tanto el desarrollo de sistemas volcano-plutónicos como la depositación simultánea de sedimentos continentales. En el contexto regional es posible relacionar temporalmente las litologías ígneas aflorantes en el área del municipio de Pailitas, con el arco magmático calco-alcalino de edad Jurásico Temprano-Medio, representado hoy en los cuerpos ígneos coetáneos presentes en la Sierra Nevada de Santa Marta, Norosí, San Martín, San Lucas, Ibagué Sur.

Palabras clave: Colombia; Arco magmático; Formación Noreán; Geocronología U-Pb.

\section{Contributions to the age knowledge of plutonic, hypabyssal and volcanoclastic igneous bodies outcropping in the Pailitas town area (Cesar, Colombia)}

\begin{abstract}
In the Pailitas town area (Cesar Department), located between the Eastern and Central Colombian mountain ranges, outcrop mostly Precambrian (at high- and low-grade metamorphism) and Mesozoic rocks (plutonic, hypabyssal, volcanoclastic, volcano-sedimentary and continental sedimentary), these last ones grouped into the so-call Norean Formation.

The relatively wide space distribution of this unit, the relationship of its lithologies, the crystallization ages of its related-plutonic and hypabyssal rocks (zircon U-Pb ages of 176.7 $\pm 2.2 \mathrm{Ma}$ and 176.0 $\pm 2.1 \mathrm{Ma}$, respectively), as well as the maximum stratigraphic age of the associated-volcano-sedimentary rocks (with the youngest detrital zircons U-Pb ages' peak at about $190 \mathrm{Ma}$ ), suggest this unit was formed in an extensive tectonic environment, which allowed the development of volcano-plutonic systems and simultaneously the deposition of continental sediments. In the regional context, it is possible to relate in time the igneous lithologies outcropping in the Pailitas town area with the calco-alkaline magmatic arc of Early-Middle Jurassic age, today represented in the coeval igneous bodies outcropping in the Sierra Nevada de Santa Marta, Norosí, San Martín, San Lucas, Ibague areas.
\end{abstract}

Keywords: Colombia; Magmatic arc; Norean Formation; U-Pb Geochronology.

${ }^{1}$ Universidad Industrial de Santander, Bucaramanga, Colombia. (*) williamdavidavellaneda@gmail.com, camilo2188225@correo.uis.edu.co, andreaayala1026@hotmail.com, lcmantil@uis.edu.co, rbernalo@uis.edu.co, favelanp@uis.edu.co

${ }^{2}$ Agencia Nacional de Hidrocarburos (Proyecto 454-2017; Apoyo a Formación de Recurso Humano), Bucaramanga, Colombia. 


\section{Introducción}

Los estudios geológicos de las rocas ígneas de edad Triásico-Jurásico aflorantes a lo largo de los Andes de Colombia (Figura 1), han identificado la presencia de por lo menos tres arcos magmáticos calco-alcalinos propios de ambientes de supra-subducción: (a) uno de aproximados 205-194 Ma (cuerpos ígneos del Macizo de Santander y Mocoa); (b) otro de aproximados 194-
174 Ma (cuerpos ígneos de la Sierra Nevada de Santa Marta, Norosí, San Martín, San Lucas, Ibagué Sur) y; (c) otro de aproximados 167-149 Ma (cuerpos ígneos de Segovia-Ibagué Norte; Leal-Mejía, 2011; Van der Lelij, 2013; Spikings et al., 2015). El emplazamiento de estos cuerpos se considera han sido controlados por fallas mayores y sistemas de sutura preexistentes, tales como las fallas de Palestina y Bucaramanga-Santa Marta-Suaza (Aspden et al., 1987; Cediel et al., 2003).

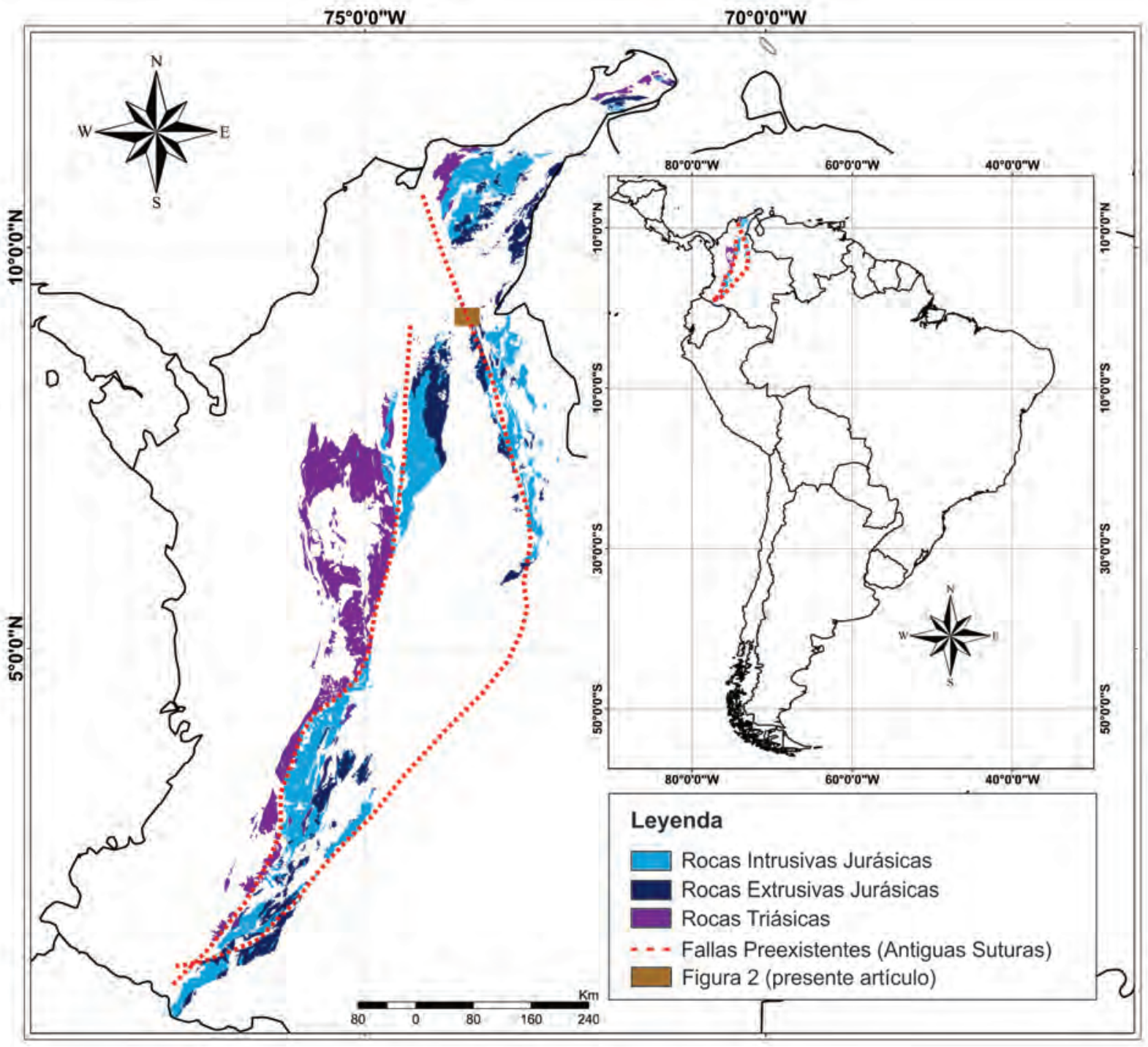

Figura 1. Esquema geológico donde se resalta la distribución espacial de las rocas ígneas asociadas a los diferentes arcos magmáticos de edad Triásico-Jurásico, reconocidos en los Andes de Colombia. El recuadro indica la ubicación del área objeto del presente estudio. Modificado de Leal-Mejía (2011). 
En el área del municipio de Pailitas (Figura 2), localizada entre las Cordilleras Oriental y Central de Colombia (inmediaciones al Macizo de Santander, al W de la falla de Bucaramanga, y la Serranía de San Lucas, al E de la falla de Palestina), afloran rocas ígneas (plutónicas, hipoabisales, volcanoclásticas y volcanosedimentarias), las cuales no han sido datadas por métodos absolutos, pero a las cuales se les asignó por extrapolación una edad Jurásico (INGEOMINASUIS, 2006a).

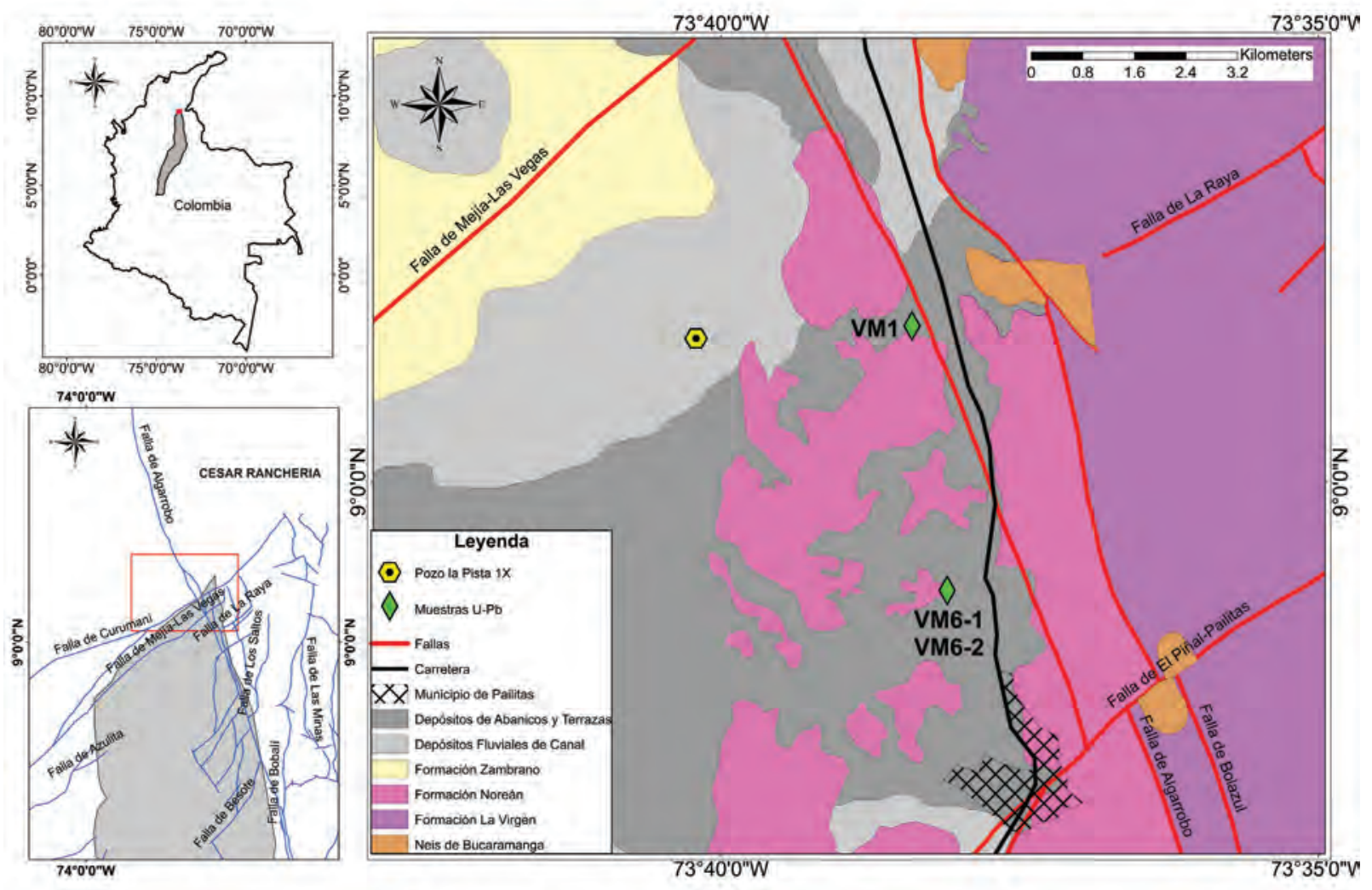

Figura 2. Esquema geológico y proyección de las fallas regionales del área de estudio, en el cual se señala la ubicación de los puntos de muestreo realizados en el marco del presente estudio, para análisis geocronológicos mediante U-Pb en zircones. Modificado de INGEOMINAS-UIS (2006a).

El objetivo del presente estudio es contribuir al conocimiento de las edades absolutas (mediante dataciones $\mathrm{U}-\mathrm{Pb}$ en zircones), principalmente de los cuerpos ígneos aflorantes en cercanías del municipio de Pailitas(representados en rocasplutónicas, hipoabisales, volcanoclásticas y volcanosedimentarias), con lo cual se aportará al entendimiento de la distribución espacial y temporal de los sistemas volcano-plutónicos asociados a los arcos magmáticos del Triásico-Jurásico previamente referidos

\section{Antecedentes y contexto geológico}

El emplazamiento de los arcos magmáticos de supra-subducción del Triásico Tardío-Jurásico en los Andes septentrionales (especialmente los Andes de
Colombia), ha sido recientemente un tema de arduo debate. Por un lado, algunos autores consideran que el eje de los arcos magmáticos migró progresivamente al oeste, debido al desplazamiento en la misma dirección del eje del canal de subducción (Spikings et al., 2015); mientras que otros autores indican que el eje de los arcos magmáticos presentó variaciones, es decir, avances al oeste y retrocesos al este (Rodríguez et al., 2018), en respuesta a las diferencias en el ángulo de subducción de la litosfera oceánica; o como respuesta a una tectónica propia de una convergencia oblicua entre la placa oceánica y la placa continental (Bustamante et al., 2017).

De los tres arcos magmáticos de edad Triásico TardíoJurásico, referidos en el apartado Introducción, se considera que el arco magmático de edad entre 194- 
174 Ma (representado en los cuerpos ígneos de la Sierra Nevada de Santa Marta, Norosí, San Martín, San Lucas, Ibagué Sur), fue el que dejó un amplio registro tanto de rocas plutónicas, como de rocas hipoabisales, volcanoclásticas y volcanosedimentarias, lo cual permite asociar este arco con un ambiente tectónico de extensión (debido al desarrollo de un roll-back?). Este contexto tectónico ha sido considerado por diferentes autores como favorable para la formación de una zona volcano-plutónica de mayor amplitud, a diferencia de un ambiente de subducción generador de convergencia y apilamiento cortical, en donde la amplitud del arco volcano-plutónico es comparativamente más reducido (Bustamante et al., 2017; Byrne et al., 2018).

La posibilidad de contar con rocas ígneas de diferentes niveles de profundidad en el área objeto del presente estudio (rocas plutónicas, subvolcánicas, volcanoclásticas y volcanosedimentarias), potencialmente relacionadas con un mismo sistema volcano-plutónico en evolución (en respuesta a una tectónica extensiva), hace de este sector de la corteza un lugar atractivo, entre otros propósitos, para el desarrollo de diferentes estudios relacionados con la evolución de los magmas.

Con el propósito de contextualizar más detalladamente el área objeto del presente estudio, a continuación se hace referencia a los rasgos geológicos locales que guardan relación directa con los objetivos de la actual investigación. En este sentido, es importante ante todo resaltar que en el sector del municipio de Pailitas afloran rocas de bajo grado de metamorfismo agrupadas dentro de la denominada Formación La Virgen (filitas pelíticas, semipelíticas, cuarzosas y localmente rocas metacarbonatadas), a las cuales se les asignó una edad relativa del Paleozoico Temprano (INGEOMINASUIS, 2006b). Sin embargo, estudios recientes aún inéditos (Ayala, A., comunicación verbal), apuntan a que estas rocas son de edad Precámbrica. En términos generales, estas rocas metamórficas de bajo grado se consideran como las rocas hospedadoras de los cuerpos ígneos plutónicos presentes en el área objeto de la presente investigación.

Las rocas ígneas plutónicas aflorantes en el área de estudio (plancha geológica No. 55), temporalmente se han relacionado con el arco magmático de Norosí, considerado de edad Jurásico (Leal-Mejía, 2011). Rocas de la misma edad, de ambiente continental (tanto sedimentarias, volcanosedimentarias, volcanoclásticas, como localmente rocas hipoabisales y efusivas), han sido agrupadas dentro de la denominada Formación Noreán (Clavijo, 1995) y consideradas de edad Jurásico Temprano a Medio (INGEOMINAS-UIS, 2006b; LealMejía, 2011; Correa-Martínez et al., 2019).

En el contexto de lo anteriormente referido, y tal como ya fue señalado previamente, el objetivo del presente estudio es aportar edades absolutas tanto de los cuerpos plutónicos e hipoabisales aflorantes en el sector del municipio de Pailitas, como también determinar la máxima edad estratigráfica de las rocas volcanosedimentarias/sedimentarias continentales de la Formación Noreán, a partir de las edades U-Pb de sus circones detríticos.

\section{Métodos analíticos}

Con el propósito de estudiar las relaciones entre las diferentes litologías presentes en el área de estudio, se realizaron trabajos de campo para fines de reconocimiento de sus variedades litológicas, relaciones entre éstas y evidentemente también para fines de muestreo. Con este mismo propósito se realizó una revisión de la información geológica de los pozos de perforación ANH-VMM-WP271, ANH-VMM-EL TRIUNFO-1X y ANH-VMM- LA PISTA-1X, suministrada por la Agencia Nacional de Hidrocarburos (ANH).

El análisis de muestras de mano y algunas láminas delgadas estudiadas mediante microscopía óptica, se realizó utilizando una lupa binocular marca NIKON SMZ645 y un microscopio de luz transmitida marca NIKON ECLIPSE E200 50/POL con cámara y pantalla incorporada, los cuales hacen parte del laboratorio de microscopía óptica de la Escuela de Geología de la Universidad Industrial de Santander (UIS). La extracción de circones se realizó utilizando los métodos tradicionales en ZirChron LLC (Tucson, AZ), mientras que las dataciones $\mathrm{U}-\mathrm{Pb}$ en circones, fueron realizadas utilizando la técnica LA-ICP-MS (Laser Ablation Inductively Coupled Plasma Mass Spectrometry), en el laboratorio de geoquímica isotópica de la Universidad Estatal de Washington, siguiendo los procedimientos analíticos descritos por Chang et al. (2006). Los detalles del correspondiente procedimiento analítico, también se resumen en el apartado Metodología, documentado en Mantilla-Figueroa et al. (2013). 


\section{Resultados}

\section{Generalidades de las unidades litológicas aflorantes en el área de estudio}

Las rocas más antiguas aflorantes en el área de estudio están representadas por las unidades litológicas denominadas Gneis de Bucaramanga y la Formación La Virgen. Estas rocas han sido consideradas en edad de finales del Neo- y Meso-Proterozóico ( 1300-900 Ma; según Cordani et al., 2005; Ordóñez-Carmona et al., 2006) y del Ordovícico-Silúrico $(\sim 480-420 \mathrm{Ma}$, según Clavijo et al., 2008), respectivamente. El Gneis de Bucaramanga se compone de rocas metamórficas de alto grado (Facies Anfibolita), mayoritariamente gneises y esquistos anfibolíticos, cuarzo-feldespáticos, pelíticos y algunas cuarcitas. La Formación La Virgen se compone de rocas metamórficas de muy bajo y bajo grado (Facies Sub-esquistos Verdes/Esquistos Verdes), mayoritariamente filitas, metarenitas e intercalaciones de metaconglomerados (Clavijo et al., 2008).

Rocas más recientes (sin metamorfismo) observadas en el área de estudio, se relacionan con la denominada
Formación Noreán, la cual se formó en un ambiente extensivo (hundimiento y ensanchamiento progresivo de la cuenca), cuyo máximo desarrollo tuvo lugar durante el Jurásico Temprano-Jurásico Medio (Clavijo, 1996). Esta unidad aflora en gran parte de la zona estudiada y se presenta a ambos lados del Sistema de Fallas de Bucaramanga-Santa Marta (SFBSM) a manera de franjas de dirección NNW-SSE, en donde se compone principalmente de materiales propios de un volcanismo explosivo (materiales volcanoclásticos y volcanosedimentarios), los cuales junto a depósitos de flujos de lodo y fluviolacustres conforman una potente secuencia de más de $4.000 \mathrm{~m}$ de espesor (Pindell y Kennan, 2001; Acosta, 1995; Clavijo et al., 2008). Cuerpos ígneos plutónicos e hipoabisales cortan localmente las rocas referidas asignadas a la Formación Noreán, lo que podría indicar que estos cuerpos ígneos son ligeramente posteriores (ver Figura 3A, 3B, 3C, 3D). No obstante, puntualmente estas relaciones de corte no son claras y por el contrario podrían sugerir una coetaneidad entre las rocas ígneas (plutónicas e hipoabisales) y las rocas volcanoclásticas/volcaconosedimentarias/sedimentarias de la Formación Noreán.
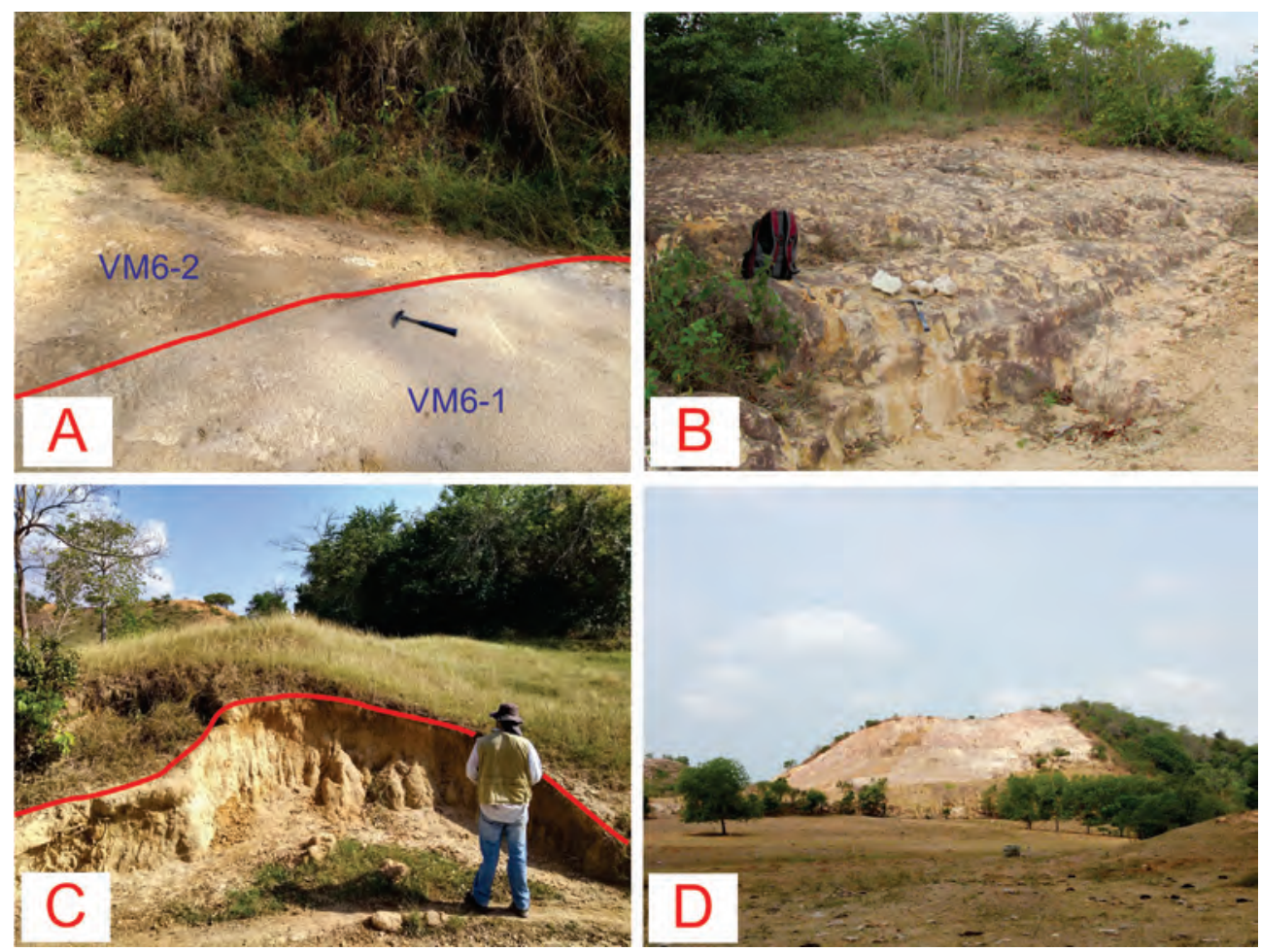

Figura 3. Aspecto general de los cuerpos ígneos aflorantes en el área de estudio A. Relación de corte entre dos cuerpos ígneos de composición granítica (cuerpo plutónico VM6-1 y cuerpo hipoabisal VM6-2), con diferentes intensidades de alteración supérgena. B, C y D. Aspecto general en campo de los cuerpos ígneos graníticos aflorantes en área de estudio, en los cuales se evidencia localmente su perfil de meteorización (con desarrollo de horizontes edáficos locales, como se indica en la Figura 3C). 
Para fines de explorar la petrografía de las rocas mayoritarias que afloran en el área de estudio, se colectaron tres muestras al norte del municipio de Pailitas (departamento del Cesar; ver Figura 2; dos muestras de cuerpos ígneos félsicos VM6-1 y VM62 y una de un cuerpo volcanosedimentario). La muestra VM6-1 clasificada como un sienogranito según Streckeisen (1979) con textura fanerítica y con evidencias locales de alteraciones hidrotermales hipógenas y supérgenas; es holocristalino, con cristales mayoritariamente subhedrales, algunos de ellos de 1 a $2 \mathrm{~mm}$, compuestos principalmente de feldespato potásico (38\%), plagioclasa (15\%) (estos dos últimos alterados a sericita), cuarzo (45\%) y con minerales accesorio de biotita y opacos (Figura 4A y
4B). La muestra VM6-2 (Figura 4C y 4D) corresponde a un dique riolítico que intruye al cuerpo granítico ya referido. Esta roca presenta una textura porfiriticaafanítica, cuyos fenocristales y microfenocristales se componen principalmente por plagioclasa (20\%), feldespato potásico (36\%) (altamente sericitizados) y cuarzo (41\%) (en menor proporción cristales de biotita y minerales secundarios de clorita y epidota). La muestra de roca volcanosedimentaria (muestra VM1) corresponde a una toba lítica (Figura 4E y 4F), con texturas microporfídica y fragmetal, compuesta principalmente por microcristales de cuarzo, feldespato potásico, plagioclasa y fragmentos líticos inmersos en una matriz microcristalina a vítrea. Los fragmentos líticos son principalmente juveniles de tobas.
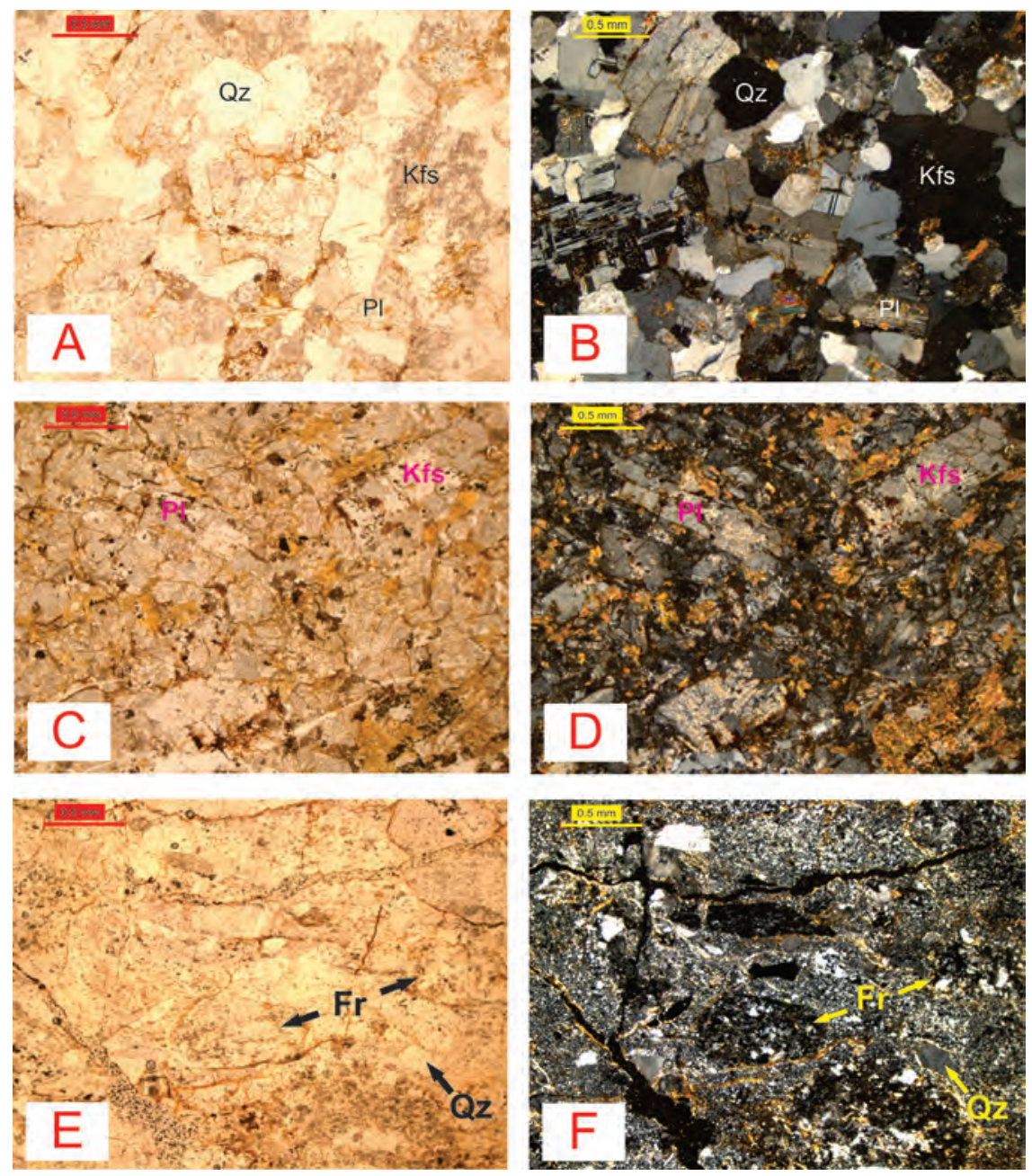

Figura 4. Microfotografías de los cuerpos ígneos aflorantes en el área de estudio A. Muestra VM6-1 granito holocristalino, con cristales subhedrales de feldespato potásico (Kfs), plagioclasa (Pl) y cuarzo (Qtz), en nicoles paralelos B. Muestra VM61 en nicoles cruzados C. Muestra VM6-2 dique riolítico porfirítico, muy alterado, con fenocristales y microfenocristales de plagioclasa ( $\mathrm{Pl}$ ), feldespato potásico (Kfs) y cuarzo (Qtz), en nicoles paralelos D. Muestra VM6-2 en nicoles cruzados E. Muestra VM1 toba lítica, con texturas microporfídica y fragmetal, compuesta por microcristales principalmente de cuarzo (Qtz), feldespato potásico, plagioclasa y fragmentos líticos (Fr). F. Muestra VM1 en nicoles cruzados. Abreviatura de los minerales según Whitney y Evans (2010). 


\section{Geocronología U-Pb}

Los datos analíticos y las relaciones isotópicas $\mathrm{U}-\mathrm{Pb}$ determinados en circones ígneos (Figura 5) y detríticos de las tres muestras analizadas mediante la técnica LA-ICP-MS (muestras VM1, VM6-1, VM6-2), se resumen en los Anexos 1, 2 y 3 y sus representaciones se proyectan en las Figuras 6, 7 y 8 . Estas muestras analizadas fueron colectadas al norte del casco urbano del municipio de Pailitas (ver coordenadas de localización de las muestras en la Tabla 1).

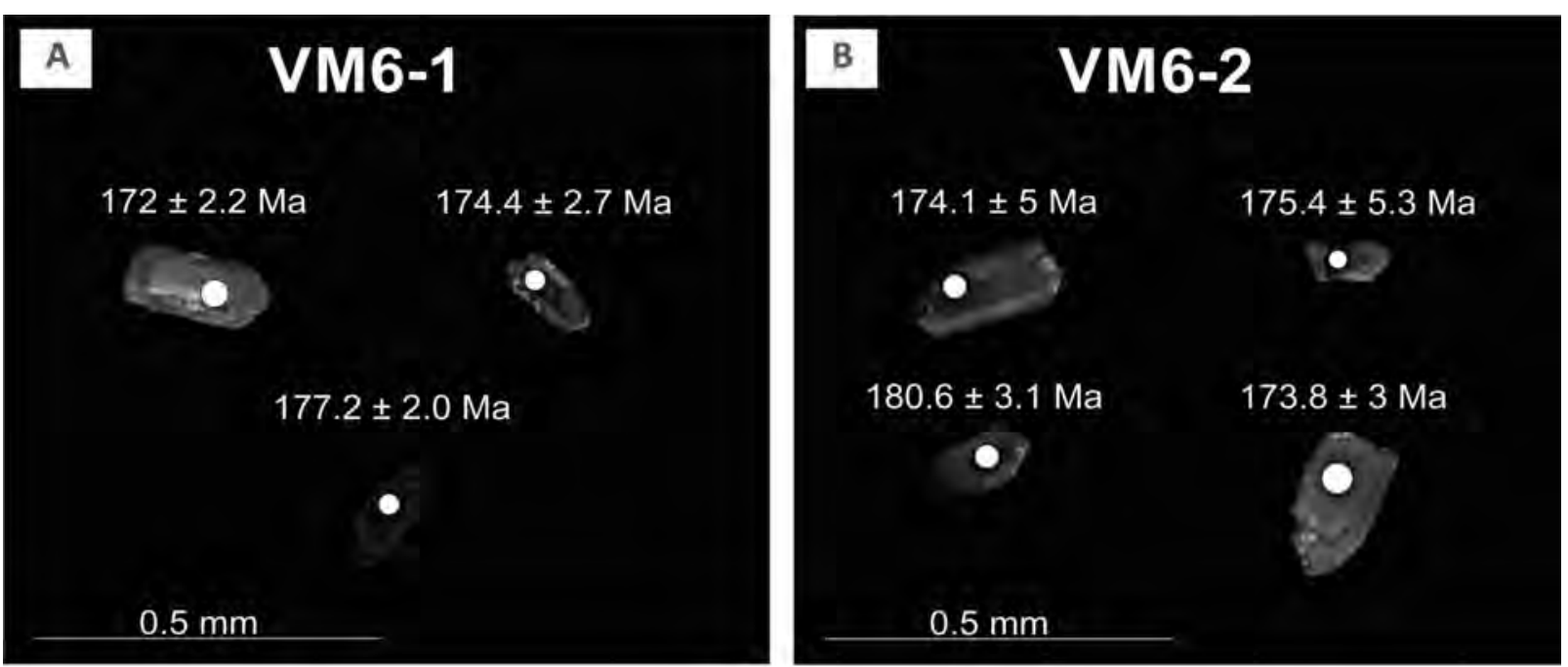

Figura 5. Imágenes de catodoluminiscencia (CL) de circones representativos estudiados. Círculos blancos indican lugares de ablación. A. Muestra VM6-1. B. Muestra VM6-2.
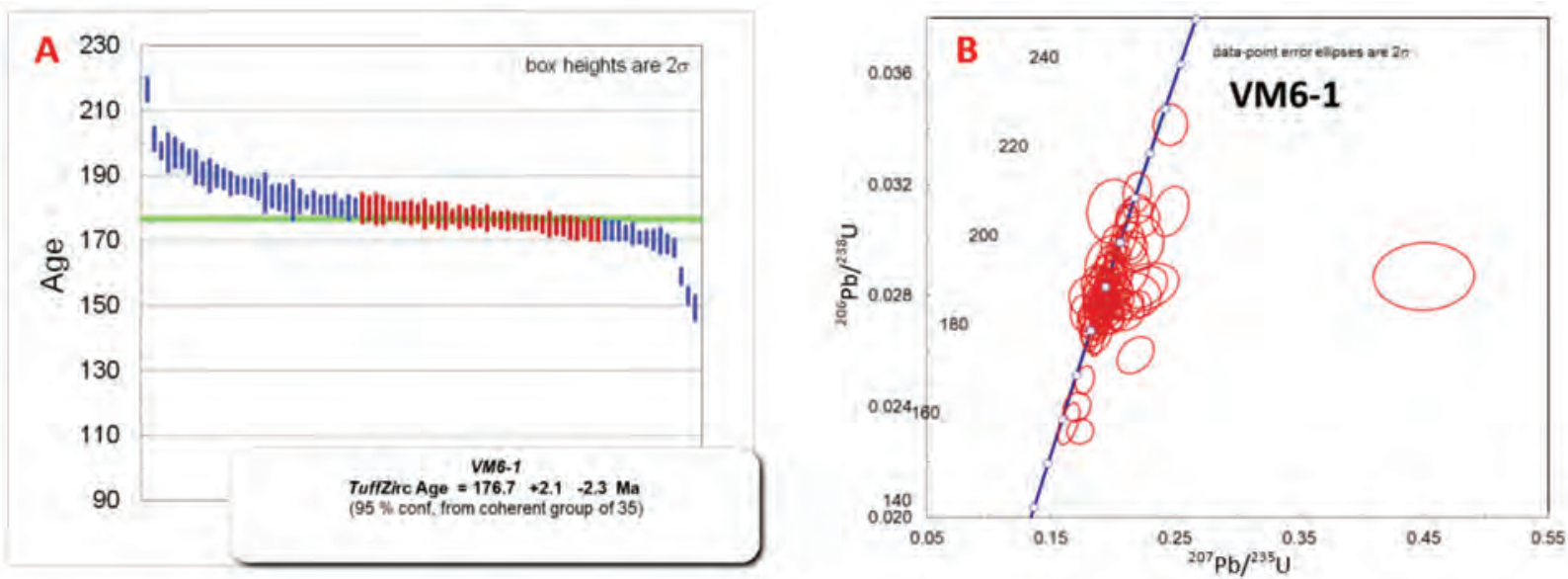

Figura 6. Edades U-Pb obtenidas a partir del análisis de circones de la muestra VM6-1 (sienogranito), mediante la técnica LAICP-MS. A. Diagrama de distribución de las edades obtenidas (error $2 \sigma$ ), en la cual se muestra la dominancia de las edades en torno a 176,7 $\pm 2,2$ Ma. B. Diagrama concordia U-Pb a partir de circones, donde se muestran las diferentes edades heredades y la edad de cristalización del cuerpo plutónico analizado. 

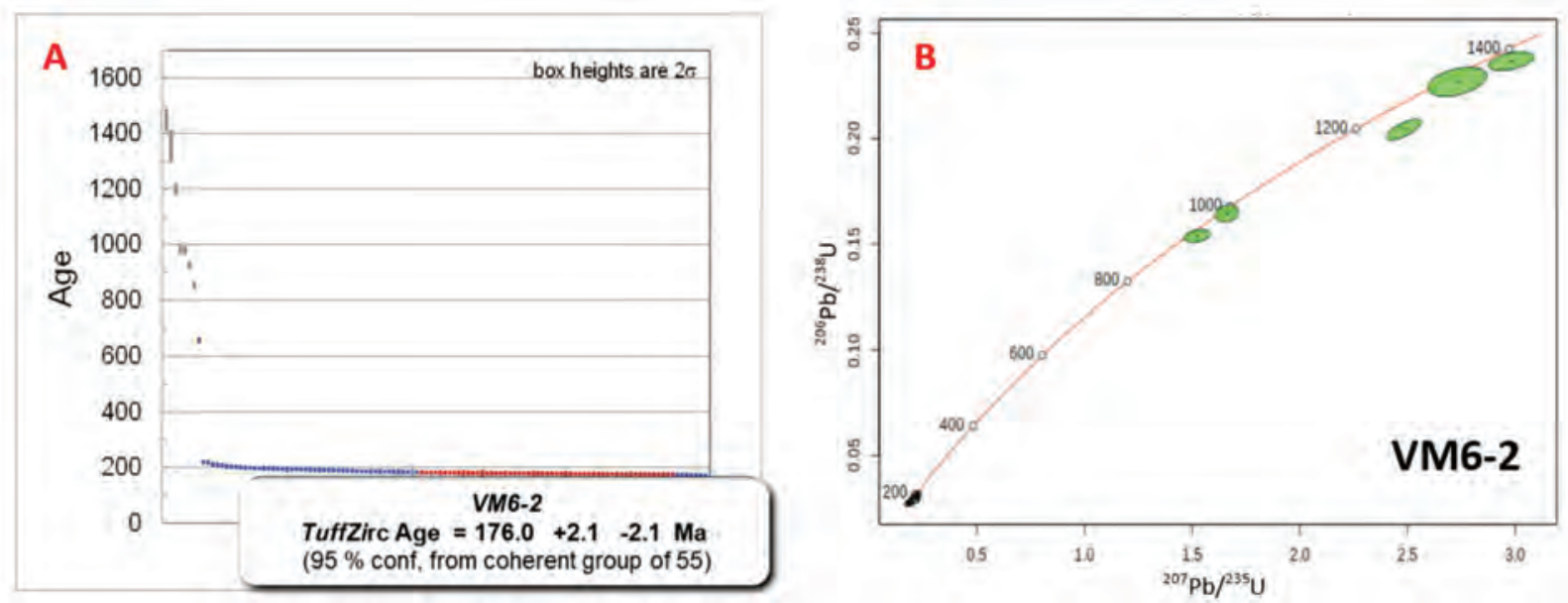

Figura 7. Edades U-Pb obtenidas a partir del análisis de circones de la muestra VM6-2 (dique riolítico), mediante la técnica LAICP-MS. A. Diagrama de distribución de las edades obtenidas (error $2 \sigma$ ), en la cual se muestra la dominancia de las edades en torno a 176,0 $\pm 2,1$ Ma. B. Diagrama concordia U-Pb a partir de circones, donde se muestran las diferentes edades heredades y la edad de cristalización del cuerpo ígneo hipoabisal analizado.
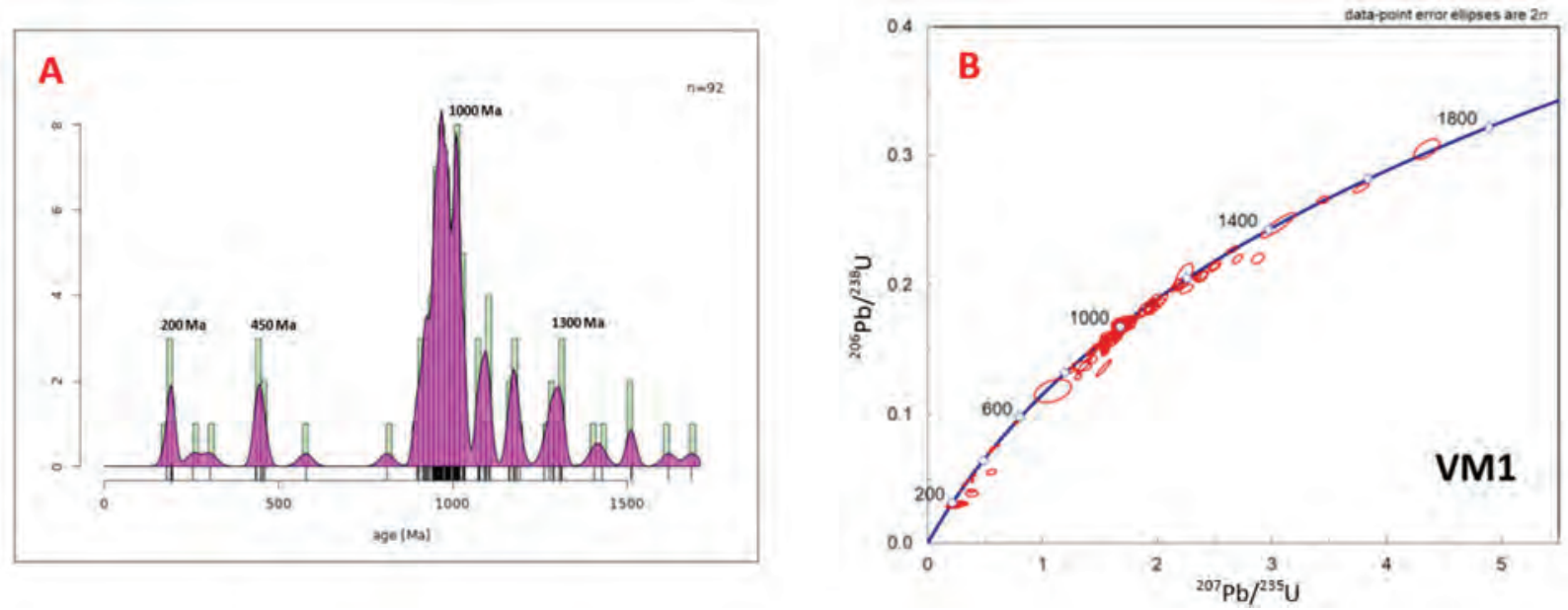

Figura 8. A. Distribución de los picos de edades obtenidas a partir del análisis de circones detríticos presentes en la muestra VM1. B. Diagrama de concordia U-Pb, en el cual se muestran las diferentes edades de los circones detríticos analizados.

Tabla 1. Coordenadas y localización geográfica de las litologías colectadas para análisis mediante geocronología U-Pb en circones.

\begin{tabular}{|c|c|c|c|c|c|c|c|}
\hline \multirow[b]{2}{*}{ Muestra } & \multirow[b]{2}{*}{ Tipo de roca } & \multicolumn{3}{|c|}{ Coordenadas locales* } & \multicolumn{2}{|c|}{ Coordenadas $^{\circ}$} & \multirow{2}{*}{$\begin{array}{c}\text { Localización } \\
\text { geográfica }\end{array}$} \\
\hline & & $\mathbf{X}$ & $\mathbf{Y}$ & $\begin{array}{c}\mathrm{Z} \\
(\mathrm{msnm})\end{array}$ & Latitud & Longitud & \\
\hline VM1 & Volcanosedimentaria & 1.048 .090 & 1.489 .452 & 65 & $9^{\circ} 1^{\prime} 18.29^{\prime \prime} \mathrm{N}$ & $73^{\circ} 38^{\prime} 24.10^{\prime \prime O}$ & Pailitas, Cesar \\
\hline VM6-1 & Ígnea-Plutónica & 1.048 .425 & 1.485 .320 & 69 & $8^{\circ} 59^{\prime} 5.70^{\prime \prime} \mathrm{N}$ & $73^{\circ} 38^{\prime} 6.46^{\prime \prime} \mathrm{O}$ & Pailitas, Cesar \\
\hline VM6-2 & Ígnea-Volcánica & 1.048 .425 & 1.485 .320 & 69 & $8^{\circ} 59^{\prime} 5.70^{\prime \prime} \mathrm{N}$ & $73^{\circ} 38^{\prime} 6.46^{\prime \prime} \mathrm{O}$ & Pailitas, Cesar \\
\hline
\end{tabular}

*Coordenadas Planas con Datum Bogotá (Bogotá 1975/Colombia Bogotá zone (21897)

${ }^{\circ}$ Coordenadas Datum WGS84 (EPSG 4326) 
En la muestra VM6-1 analizada, clasificada petrográficamente como un cuerpo ígneo sienogranito (Figura 4A y 4B), se realizaron un total de 82 análisis (Anexo 1), de las cuales se consideraron óptimas para la interpretación aquellas con discordancias inferiores al $10 \%$ (Spencer et al., 2016) y relaciones $\mathrm{Th} / \mathrm{U}$ propias de circones ígneos entre 0,3 y 1,7 (Rubatto, 2002). La edad de concordia obtenida en esta muestra

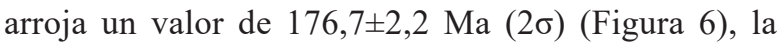
cual es interpretada como una edad de cristalización del cuerpo ígneo (edad Toarciense).

En la muestra VM6-2, correspondiente a un dique riolítico porfirítico (Figura 4C y 4D), se realizaron un total de 118 ablaciones (Anexo 2), cuyos datos fueron igualmente sometidos a los mismos tratamientos ya referidos anteriormente. La edad de cristalización obtenida para este cuerpo porfirítico, arrojó un valor

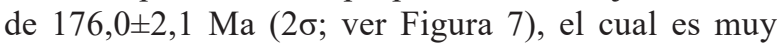
cercano a la edad previamente reportada para el cuerpo plutónico antes referido (edad Toarciense).

Las edades de los circones heredados presentes en las dos muestras antes mencionadas $(1730 \pm 160 \mathrm{Ma}$, $1446 \pm 37$ Мa, $1353 \pm 54$ Мa, $1376 \pm 28$ Ma, $1007 \pm 43$ Ma, $973 \pm 48$ Ma y $600 \pm 61 \mathrm{Ma}$ ), se interpretan como edades heredadas de las rocas metamórficas precámbricas referidas en el apartado antecedentes.

En la muestra VM1, correspondiente a una toba lítica (VM1), se hicieron un total de 146 análisis en circones detríticos (Anexo 3) (Figura 8). Basados en las edades $\mathrm{U}-\mathrm{Pb}$ obtenidas, es posible determinar que

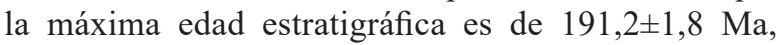
correspondiente al Sinemuriense (Jurásico Temprano). La presencia de otros circones detríticos con picos de edades del Neo- y Meso- Proterozoico (577,7 $\pm 5,5 \mathrm{Ma}$ y $1564 \pm 15 \mathrm{Ma}$ ) (Figura $8 \mathrm{~A}$ ) indican una procedencia de rocas más antiguas, como por ejemplo las unidades Gneis de Bucaramanga y Esquistos del Silgará (Mantilla-Figueroa et al., 2016). En cuanto a los picos de edades paleozoicas que oscilan entre $255,5 \pm 2,1$

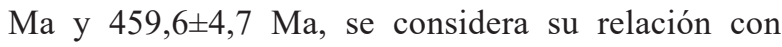
los eventos magmáticos ocurridos durante esta era (Cardona et al., 2016).

\section{Conclusiones}

En el área del municipio de Pailitas (departamento del Cesar) afloran rocas plutónicas, subvolcánicas, volcanoclásticas y sedimentarias continentales, las cuales han sido agrupadas dentro de la Formación Noreán. La amplia variación litológica de esta unidad y su afinidad con sistemas volcano-plutónicos calcoalcalinos, permite señalar que estas rocas se formaron en un ambiente tectónico extensivo.

Las edades de cristalización de los circones ígneos de los cuerpos plutónicos (edades U-Pb en circones de $176,7 \pm 2,2 \mathrm{Ma}$ ), hipoabisales (edades U-Pb en circones de $176,0 \pm 2,1 \mathrm{Ma}$ ), y la máxima edad estratigráfica (o máxima edad de depositación) de las rocas volcanosedimentarias aflorantes en el área de estudio (circones detríticos con edades U-Pb más recientes alrededor de $190 \mathrm{Ma}$ ), apuntan a que esta unidad se relaciona temporalmente con el arco magmático que dio origen a los diferentes cuerpos ígneos de la Sierra Nevada de Santa Marta, Norosí, San Martín, San Lucas e Ibagué Sur, principalmente.

\section{Agradecimientos}

Los autores expresan su profundo agradecimiento a la Escuela de Geología y en general a toda la Universidad Industrial de Santander (UIS), por su gran apoyo técnico durante la realización del presente estudio. Este trabajo contó con el apoyo financiero del proyecto titulado: "Certificación de Estratigrafía Física y de Calidad de los núcleos de perforación recuperados por la ANH en las Cuencas Valle inferior del Magdalena, Cesar y Ranchería", el cual hace parte del Contrato No. FP44842-454-2017, celebrado entre COLCIENCIAS, La Universidad Industrial de Santander (UIS) y la Fiduciaria La Previsora S.A; el cual a su vez se deriva del Convenio No. 730/327 de 2016, celebrado entre la ANH (La Agencia Nacional de Hidrocarburos), COLCIENCIAS (actualmente MINCIENCIAS) y la Fiduciaria La Previsora S.A.

\section{Referencias}

Acosta, J. (1995). Structural evolution of the Colombian Eastern Cordillera Foothills. MSc Thesis. College of Science, Technology and Medicine, University of London.

Aspden, J.A.; McCourt, W.J.; Brook, M. (1987). Geometrical control of subduction-related magmatism: the Mesozoic and Cenozoic Plutonic History of Western Colombia. Journal Geological Society, 144, 893-905. 
Bustamante, C.; Archanjo, C.J.; Cardona, A.; Bustamante, A.; Valencia, V.A. (2017). U-Pb Ages and Hf Isotopes in zircons from parautochthonous Mesozoic terranes in the Western margin of Pangea: Implications for the terrane configurations in the Northern Andes. The Journal of Geology, 125(5), 487-500. doi: 10.1086/693014

Byrne, T.; Underwood, M.B.; Fisher, D.; McNeill, L.; Saffer, D.; Ujiie, K.; Yamaguchi, A. (2018). Geology and tectonics of subduction zones: A tribute to Gaku Kimura. Vol. 534. Boulder: Geological Society of America. doi: 10.1130/ SPE534

Cardona, A.; Valencia, V.; Lotero, A.; Villafañez, Y.; Bayona, G. (2016). Provenance of middle to late Palaeozoic sediments in the northeastern Colombian Andes: implications for Pangea reconstruction. Internatonal Geology Review, 58(15), 1914-1939. doi: 10.1080/00206814.2016.1190948

Cediel, F.; Shaw, R.P.; Cáceres, C. (2003). Tectonic assembly of the Northern Andean Block. In: C. Bartolini; R. Buffler; J. Blickwede (eds.). The Circum-Gulf of Mexico and the Caribbean: Hydrocarbon Habitats, Basin Formation and Plate Tectonics (pp. 815-848). AAPG Memoir 79.

Chang, Z.; Vervoort, J.D.; McClelland, W.C.; Knaack, C. (2006). U-Pb dating of zircon by LA-ICP-MS. Geochemistry, Geophysics, Geosystems, 7(5). doi: 10.1029/2005GC001100

Clavijo, J. (1996). Mapa Geológico de Colombia. Plancha 75 - Aguachica. Escala 1:100.000. Memoria explicativa. INGEOMINAS, Bucaramanga.

Clavijo, J. (1995). La Formación Noreán: Nueva evidencia de volcanismo explosivo en la paleocuenca del Magdalena (Colombia) y su relación con otras unidades del Jurásico norandino. IX Congreso Latinoamericano de Geología. Caracas, Venezuela.

Clavijo, J.; Mantilla, L.; Pinto, J.; Bernal, L.; Pérez, A. (2008). Evolución geológica de la Serranía de San Lucas, norte del Valle Medio del Magdalena y noroeste de la Cordillera Oriental. Boletín de Geología, 30(1), 45-62.
Cordani, U.G.; Cardona, A.; Jiménez, D.M.; Liu, D.; Nutman, A.P. (2005). Geochronology of Proterozoic basement inliers in the Colombian Andes: tectonic history of remnants of a fragmented Grenville belt. Geological Society, London, Special Publications, 246, 329-346. doi: 10.1144/GSL.SP.2005.246.01.13

Correa-Martínez, A.M.; Rodríguez, G.; Arango, M.I.; Zapata-García, G. (2019). Petrografía, geoquímica y geocronología $\mathrm{U}-\mathrm{Pb}$ de las rocas volcánicas y piroclásticas de la Formación Noreán al NW del Macizo de Santander, Colombia. Boletín de Geología, 41(1), 29-54. doi: 10.18273/revbol. v41n1-2019002

INGEOMINAS-UIS. (2006a). Geología de la Plancha 55 El Banco. Escala 1:100.000. Mapa Geológico. INGEOMINAS, Bogotá.

INGEOMINAS-UIS. (2006b). Cartografía geológica de $9.600 \mathrm{~km}^{2}$ de la Serranía de San Lucas: Planchas 55 (El Banco), 64 (Barranco de Loba), 85 (Simití) y 96 (Bocas del Rosario). Aporte a su evolución geológica. Memoria explicativa de la Plancha 55 El Banco. INGEOMINAS, Bogotá.

Leal-Mejía, H. (2011). Phanerozoic gold metallogeny in the Colombian Andes: A tectono- magmatic approach. PhD Thesis, Universitat de Barcelona, España.

Mantilla-Figueroa, L.C.; Bissig, T.; Valencia, V.; Hart, C. (2013). The magmatic history of the VetasCalifornia mining district; Santander Massif, Eastern Cordillera, Colombia. Journal of South American Earth Sciences, 45, 235-249. doi: 10.1016/j.jsames.2013.03.006

Mantilla-Figueroa, L.C.; García-Ramírez, C.A.; Valencia, V.A. (2016). Nuevas evidencias que soportan la escisión de la Formación Silgará y propuesta de un nuevo marco estratigráfico para el basamento metamórfico del Macizo de Santander (Cordillera Oriental de Colombia). Revista de la Academia Colombiana de Ciencias Exactas, Físicas y Naturales, 40(155), 320-336. doi: 10.18257/raccefyn.303

Ordóñez-Carmona, O.; Restrepo-Álvarez, J.J.; Pimentel, M.M. (2006). Geochronological and isotopical review of pre-Devonian crustal 
basement of the Colombian Andes. Journal of South American Earth Sciences, 21(4), 372-382. doi: 10.1016/j.jsames.2006.07.005

Pindell, J.L.; Kennan, L. (2001). Kinematic evolution of the Gulf of Mexico and Caribbean. In: R.H. Fillon; N.C. Rosen; P. Weimer; A. Lowrie; H. Pettingill; R.L. Phair; H.H. Roberts; H.H. van Hoom (eds.). Petroleum Systems of Deep-Water Basins-Global and Gulf of Mexico Experience (pp. 193-219). Vol. 21. SEPM Society for Sedimentary Geology. doi: $10.5724 /$ gcs.01.21.0193

Rodríguez, G.; Arango, M.I.; Zapata, G.; Bermúdez, J.G. (2018). Petrotectonic characteristics, geochemistry, and $\mathrm{U}-\mathrm{Pb}$ geochronology of Jurassic plutons in the Upper Magdalena ValleyColombia: Implications on the evolution of magmatic arcs in the NW Andes. Journal of South American Earth Sciences, 81, 10-30. doi: 10.1016/j.jsames.2017.10.012

Rubatto, D. (2002). Zircon trace element geochemistry: partitioning with garnet and the link between $\mathrm{U}-\mathrm{Pb}$ ages and metamorphism. Chemical Geology, 184(1-2), 123-138. doi: 10.1016/S00092541(01)00355-2

Spencer, C.J.; Kirkland, C.L.; Taylor, R.J. (2016). Strategies towards statistically robust interpretations of in situ U-Pb zircon geochronology. Geoscience Frontiers, 7(4), 581589. doi: 10.1016/j.gsf.2015.11.006

Spikings, R.; Cochrane, R.; Villagomez, D.; Van der Lelij, R.; Vallejo, C.; Winkler, W.; Beate, B. (2015). The geological history of northwestern South America: from Pangaea to the early collision of the Caribbean Large Igneous Province (290-75 Ma). Gondwana Research, 27(1), 95-139. doi: 10.1016/j.gr.2014.06.004
Streckeisen, A. (1979). Classification and nomenclature of volcanic rocks, lamprophyres, carbonatites, and melilitic rocks: Recommendations and suggestions of the IUGS Subcommission on the Systematics of Igneous Rocks. Geology, 7(7), 331335. doi: 10.1130/0091-7613(1979)7<331:CAN OVR>2.0.CO;2

Van der Lelij, R. (2013). Reconstructing north-western Gondwana with implications for the evolution of the Iapetus and Rheic Oceans: a geochronological, thermochronological and geochemical study. $\mathrm{PhD}$ Thesis, University of Geneva, Switzerland.

Whitney, D.L.; Evans, B.W. (2010). Abbreviations for names of rock-forming minerals. American Mineralogist, 95(1), 185-187. doi: 10.2138/ am.2010.3371

William David Avellaneda-Cáceres

ORCID: 0000-0002-0787-2122

Camilo Alberto Anaya-Arias

ORCID: 0000-0002-7256-0424

Andrea Carolina Ayala

ORCID: 0000-0003-4665-3579

Luis Carlos Mantilla-Figueroa

ORCID: 0000-0002-2112-8041

Rocío Bernal-Olaya

ORCID: 0000-0002-3016-1409

Francisco Velandia

ORCID: 0000-0001-6263-0903

Trabajo recibido: noviembre 08 de 2019

Trabajo aceptado: marzo 18 de 2020 
Anexo 1. Resultados isotópicos U-Pb en circones estudiados de la muestra VM6-1 y sus correspondientes edades (análisis realizados mediante la técnica LA-ICP-MS).

\begin{tabular}{|c|c|c|c|c|c|c|c|c|c|c|c|c|c|c|c|c|c|}
\hline $\begin{array}{l}\text { Puntos de } \\
\text { análisis }\end{array}$ & $\begin{array}{c}\mathrm{U} \\
(\mathrm{ppm})\end{array}$ & $\begin{array}{l}\mathrm{U} / \\
\mathrm{Th}\end{array}$ & ${ }^{207} \mathrm{~Pb} /{ }^{235} \mathrm{U}$ & $\pm 2 \sigma$ & ${ }^{206} \mathrm{~Pb} /{ }^{238} \mathrm{U}$ & $\pm 2 \sigma$ & $\begin{array}{l}\text { Coeficiente } \\
\text { Correlación }\end{array}$ & ${ }^{238} \mathrm{U} /{ }^{206} \mathrm{~Pb}$ & $\pm 2 \sigma$ & ${ }^{207} \mathrm{~Pb} /{ }^{206} \mathrm{~Pb}$ & $\pm 2 \sigma$ & $\begin{array}{c}{ }^{207} \mathrm{~Pb} /{ }^{235} \mathrm{U} \\
\mathrm{Ma}\end{array}$ & $\begin{array}{l} \pm 2 \sigma \\
\mathrm{Ma}\end{array}$ & $\begin{array}{c}{ }^{206} \mathrm{~Pb} /{ }^{238} \mathrm{U} \\
\mathrm{Ma}\end{array}$ & $\begin{array}{l} \pm 2 \sigma \\
\mathrm{Ma}\end{array}$ & $\begin{array}{c}\text { Best } \\
\text { Age } \\
\text { Ma }\end{array}$ & $\begin{array}{c}2 \sigma \\
\text { Abs } \\
\text { Error } \\
\text { Ma }\end{array}$ \\
\hline VM6-1_24 & 39,4 & 1,8 & 0,4500 & 0,0330 & 0,0287 & 0,0010 & 0,0290 & 34,8675 & 1,2036 & 0,1154 & 0,0088 & 371,0 & 23,0 & 182,2 & 6,2 & 1730,0 & 160,0 \\
\hline VM6-1_94 & 135,8 & 0,7 & 0,1734 & 0,0087 & 0,0231 & 0,0004 & 0,0356 & 43,2713 & 0,6928 & 0,0546 & 0,0028 & 161,4 & 7,5 & 147,2 & 2,3 & 147,2 & 2,3 \\
\hline VM6-1_7 & 2090,0 & 1,7 & 0,1643 & 0,0070 & 0,0234 & 0,0006 & 0,5380 & 42,7533 & 1,1333 & 0,0517 & 0,0017 & 154,1 & 6,0 & 149,1 & 3,9 & 149,1 & 3,9 \\
\hline VM6-1_49 & 143,0 & 0,6 & 0,1711 & 0,0089 & 0,0240 & 0,0004 & 0,1207 & 41,7014 & 0,7478 & 0,0517 & 0,0026 & 160,5 & 7,9 & 152,8 & 2,7 & 152,8 & 2,7 \\
\hline VM6-1_75 & 518,0 & 1,2 & 0,1771 & 0,0061 & 0,0249 & 0,0004 & 0,2330 & 40,0962 & 0,6752 & 0,0515 & 0,0016 & 165,3 & 5,2 & 158,8 & 2,6 & 158,8 & 2,6 \\
\hline VM6-1_99 & 132,8 & 0,9 & 0,2180 & 0,0120 & 0,0259 & 0,0005 & 0,3199 & 38,6698 & 0,8075 & 0,0607 & 0,0031 & 198,7 & 9,9 & 164,6 & 3,4 & 164,6 & 3,4 \\
\hline VM6-1_62 & 1021,0 & 0,8 & 0,1871 & 0,0044 & 0,0263 & 0,0004 & 0,4527 & 37,9795 & 0,6058 & 0,0520 & 0,0012 & 174,6 & 3,9 & 167,5 & 2,7 & 167,5 & 2,7 \\
\hline VM6-1_55 & 1116,0 & 0,9 & 0,1846 & 0,0037 & 0,0265 & 0,0005 & 0,5959 & 37,6932 & 0,6536 & 0,0505 & 0,0008 & 171,8 & 3,2 & 168,8 & 2,9 & 168,8 & 2,9 \\
\hline VM6-1_8 & 121,2 & 1,2 & 0,1870 & 0,0100 & 0,0267 & 0,0006 & 0,2092 & 37,4672 & 0,8984 & 0,0511 & 0,0028 & 173,4 & 8,7 & 169,8 & 4,0 & 169,8 & 4,0 \\
\hline VM6-1_47 & 127,5 & 1,1 & 0,1850 & 0,0094 & 0,0268 & 0,0005 & 0,2432 & 37,3832 & 0,6708 & 0,0508 & 0,0027 & 171,4 & 8,0 & 170,1 & 3,0 & 170,1 & 3,0 \\
\hline VM6-1_96 & 437,0 & 1,2 & 0,1890 & 0,0055 & 0,0268 & 0,0004 & 0,3096 & 37,2995 & 0,5009 & 0,0512 & 0,0015 & 175,5 & 4,6 & 170,6 & 2,3 & 170,6 & 2,3 \\
\hline VM6-1_91 & 598,0 & 1,0 & 0,1869 & 0,0042 & 0,0269 & 0,0003 & 0,2344 & 37,2301 & 0,4020 & 0,0501 & 0,0011 & 173,8 & 3,6 & 170,8 & 1,8 & 170,8 & 1,8 \\
\hline VM6-1_53 & 134,0 & 1,2 & 0,1846 & 0,0088 & 0,0270 & 0,0005 & 0,13 & 36,9959 & 0,7117 & 0,0 & 0,0024 & 171,1 & 7,6 & 171,9 & 3,3 & 171,9 & 3,3 \\
\hline VM6-1_35 & 1173,0 & 1,0 & 0,1876 & 0,0035 & 0,0271 & 0,0004 & 0,3636 & 36,9413 & 0,4776 & 0,0502 & 0,0008 & 174,4 & 3,0 & 172,2 & 2,2 & 172,2 & 2,2 \\
\hline VM6-1_27 & 72,6 & 1,4 & 0,1910 & 0,0150 & 0,0272 & 0,0005 & 0,0001 & 36,7782 & 0,6493 & 0,0510 & 0,0042 & 175,0 & 13,0 & 172,9 & 3,0 & 172,9 & 3,0 \\
\hline VM6-1_22 & 175,0 & 1,1 & 0,1878 & 0,0091 & 0,0272 & 0,0005 & 0,0673 & 36,7647 & 0,6353 & 0,0505 & 0,0025 & 173,8 & 7,7 & 173,0 & 2,9 & 173,0 & 2,9 \\
\hline VM6-1_9 & 1240,0 & 2,7 & 0,1857 & 0,0038 & 0,0272 & 0,0005 & 0,5320 & 36,7512 & 0,6348 & 0,0497 & 0,0010 & 172,8 & 3,2 & 173,1 & 3,0 & 173,1 & 3,0 \\
\hline VM6-1_1 & 229,0 & 1,8 & 0,1804 & 0,0073 & 0,0272 & 0,0006 & 0,2974 & 36,7107 & 0,7547 & 0,0484 & 0,0020 & 167,9 & 6,2 & 173,2 & 3,5 & 173,2 & 3,5 \\
\hline VM6-1_21 & 571,0 & 1,5 & 0,1896 & 0,0058 & 0,0273 & 0,0006 & 0,1941 & 36,6569 & 0,7525 & 0,0507 & 0,0016 & 175,9 & 5,0 & 173,4 & 3,5 & 173,4 & 3,5 \\
\hline VM6-1_48 & 258,0 & 1,5 & 0,2009 & 0,0066 & 0,0273 & 0,0004 & 0,0027 & 36,6838 & 0,5383 & 0,0536 & 0,0019 & 185,4 & 5,6 & 173,4 & 2,5 & 173,4 & 2,5 \\
\hline VM6-1_52 & 87,9 & 0,8 & 0,1990 & 0,0130 & 0,0273 & 0,0006 & 0,1782 & 36,6435 & 0,7385 & 0,0532 & 0,0035 & 182,0 & 11,0 & 173,5 & 3,4 & 173,5 & 3,4 \\
\hline VM6-1_37 & 146,5 & 2,0 & 0,1763 & 0,0085 & 0,0274 & 0,0005 & 0,0001 & 36,5631 & 0,7219 & 0,0479 & 0,0026 & 164,2 & 7,4 & 173,9 & 3,4 & 173,9 & 3,4 \\
\hline VM6-1_43 & 224,0 & 1,7 & 0,1905 & 0,0083 & 0,0274 & 0,0004 & 0,1697 & 36,4697 & 0,5719 & 0,0500 & 0,0020 & 176,4 & 7,1 & 174,4 & 2,7 & 174,4 & 2,7 \\
\hline VM6-1_56 & 112,4 & 1,0 & 0,1958 & 0,0096 & 0,0274 & 0,0005 & 0,0600 & 36,4432 & 0,6242 & 0,0523 & 0,0027 & 180,3 & 8,2 & 174,4 & 3,0 & 174,4 & 3,0 \\
\hline VM6-1_65 & 109,4 & 1,4 & 0,2080 & 0,0140 & 0,0275 & 0,0006 & 0,0001 & 36,3901 & 0,8078 & 0,0552 & 0,0038 & 191,0 & 12,0 & 174,8 & 3,8 & 174,8 & 3,8 \\
\hline VM6-1_101 & 251,3 & 1,5 & 0,1893 & 0,0055 & 0,0275 & 0,0004 & 0,1148 & 36,3901 & 0,5297 & 0,0503 & 0,0016 & 175,6 & 4,7 & 174,8 & 2,5 & 174,8 & 2,5 \\
\hline VM6-1_51 & 540,0 & 1,3 & 0,1983 & 0,0049 & 0,0276 & 0,0003 & 0,4036 & 36,2450 & 0,4335 & 0,0522 & 0,0012 & 183,3 & 4,2 & 175,4 & 2,1 & 175,4 & 2,1 \\
\hline VM6-1_54 & 780,0 & 1,6 & 0,2010 & 0,0062 & 0,0276 & 0,0004 & 0,0518 & 36,2582 & 0,4864 & 0,0531 & 0,0016 & 185,6 & 5,2 & 175,4 & 2,3 & 175,4 & 2,3 \\
\hline VM6-1_66 & 771,0 & 1,2 & 0,2110 & 0,0110 & 0,0276 & 0,0004 & 0,3885 & 36,2319 & 0,5514 & 0,0565 & 0,0028 & 193,6 & 9,3 & 175,5 & 2,6 & 175,5 & 2,6 \\
\hline VM6-1_88 & 778,0 & 1,3 & 0,1865 & 0,0038 & 0,0277 & 0,0004 & 0,2961 & 36,1664 & 0,4578 & 0,0488 & 0,0010 & 173,5 & 3,3 & 175,8 & 2,2 & 175,8 & 2,2 \\
\hline
\end{tabular}




\begin{tabular}{|c|c|c|c|c|c|c|c|c|c|c|c|c|c|c|c|c|c|}
\hline $\begin{array}{l}\text { Puntos de } \\
\text { análisis }\end{array}$ & $\begin{array}{c}\mathrm{U} \\
(\mathrm{ppm})\end{array}$ & $\begin{array}{l}\mathrm{U} / \\
\mathrm{Th}\end{array}$ & ${ }^{207} \mathrm{~Pb} /{ }^{235} \mathrm{U}$ & $\pm 2 \sigma$ & ${ }^{206} \mathrm{~Pb} /{ }^{238} \mathrm{U}$ & $\pm 2 \sigma$ & $\begin{array}{l}\text { Coeficiente } \\
\text { Correlación }\end{array}$ & ${ }^{238} \mathrm{U} /{ }^{206} \mathrm{~Pb}$ & $\pm 2 \sigma$ & ${ }^{207} \mathrm{~Pb} /{ }^{206} \mathrm{~Pb}$ & $\pm 2 \sigma$ & $\begin{array}{c}{ }^{207} \mathrm{~Pb} /{ }^{235} \mathrm{U} \\
\mathrm{Ma}\end{array}$ & $\begin{array}{l} \pm 2 \sigma \\
\mathrm{Ma}\end{array}$ & $\begin{array}{c}{ }^{206} \mathrm{~Pb} /{ }^{238} \mathrm{U} \\
\mathrm{Ma}\end{array}$ & $\begin{array}{l} \pm 2 \sigma \\
\text { Ma }\end{array}$ & $\begin{array}{l}\text { Best } \\
\text { Age } \\
\text { Ma }\end{array}$ & $\begin{array}{c}2 \sigma \\
\text { Abs } \\
\text { Error } \\
\text { Ma }\end{array}$ \\
\hline VM6-1_11 & 1800,0 & 3,7 & 0,1850 & 0,0041 & 0,0277 & 0,0005 & 0,3815 & 36,1533 & 0,6012 & 0,0492 & 0,0011 & 172,3 & 3,5 & 175,9 & 2,9 & 175,9 & 2,9 \\
\hline VM6-1_90 & 327,0 & 1,8 & 0,2219 & 0,0073 & 0,0277 & 0,0004 & 0,0001 & 36,1011 & 0,5083 & 0,0580 & 0,0021 & 203,0 & 6,1 & 176,1 & 2,5 & 176,1 & 2,5 \\
\hline VM6-1_69 & 442,0 & 1,0 & 0,1894 & 0,0049 & 0,0277 & 0,0003 & 0,2794 & 36,0490 & 0,4029 & 0,0497 & 0,0013 & 175,8 & 4,2 & 176,4 & 2,0 & 176,4 & 2,0 \\
\hline VM6-1_71 & 251,4 & 0,6 & 0,1983 & 0,0063 & 0,0278 & 0,0004 & 0,0590 & 35,9842 & 0,5438 & 0,0513 & 0,0017 & 183,3 & 5,3 & 176,7 & 2,6 & 176,7 & 2,6 \\
\hline VM6-1_78 & 136,3 & 1,0 & 0,1930 & 0,0140 & 0,0278 & 0,0006 & 0,1920 & 35,9842 & 0,8028 & 0,0508 & 0,0035 & 178,0 & 12,0 & 176,7 & 3,9 & 176,7 & 3,9 \\
\hline VM6-1_2 & 173,0 & 1,3 & 0,1923 & 0,0091 & 0,0279 & 0,0005 & 0,1552 & 35,9066 & 0,6962 & 0,0511 & 0,0026 & 177,5 & 7,8 & 177,0 & 3,4 & 177,0 & 3,4 \\
\hline VM6-1_46 & 335,0 & 2,1 & 0,1981 & 0,0059 & 0,0278 & 0,0004 & 0,0730 & 35,9195 & 0,4903 & 0,0517 & 0,0017 & 183,1 & 5,0 & 177,0 & 2,4 & 177,0 & 2,4 \\
\hline VM6-1_44 & 85,4 & 0,9 & 0,1990 & 0,0110 & 0,0279 & 0,0006 & 0,0001 & 35,8938 & 0,7086 & 0,0524 & 0,0031 & 184,4 & 9,0 & 177,1 & 3,4 & 177,1 & 3,4 \\
\hline VM6-1_58 & 696,0 & 2,1 & 0,1836 & 0,0041 & 0,0279 & 0,0003 & 0,4188 & 35,8680 & 0,3988 & 0,0479 & 0,0010 & 171,0 & 3,5 & 177,2 & 2,0 & 177,2 & 2,0 \\
\hline VM6-1_19 & 96,3 & 1,1 & 0,2020 & 0,0120 & 0,0279 & 0,0007 & 0,0251 & 35,8038 & 0,8332 & 0,0526 & 0,0033 & 186,0 & 10,0 & 177,5 & 4,1 & 177,5 & 4,1 \\
\hline VM6-1_13 & 79,3 & 1,1 & 0,1820 & 0,0140 & 0,0279 & 0,0006 & 0,0001 & 35,7910 & 0,7942 & 0,0469 & 0,0037 & 168,0 & 12,0 & 177,6 & 3,9 & 177,6 & 3,9 \\
\hline VM6-1_3 & 310,0 & 1,3 & 0,1939 & 0,0057 & 0,0280 & 0,0004 & 0,1754 & 35,7526 & 0,5113 & 0,0500 & 0,0016 & 180,2 & 4,9 & 177,8 & 2,5 & 177,8 & 2,5 \\
\hline VM6-1_74 & 52,5 & 1,0 & 0,2140 & 0,0200 & 0,0280 & 0,0007 & 0,0001 & 35,7143 & 0,8929 & 0,0542 & 0,0050 & 194,0 & 16,0 & 178,0 & 4,4 & 178,0 & 4,4 \\
\hline VM6-1_17 & 165,2 & 0,6 & 0,2018 & 0,0090 & 0,0280 & 0,0004 & 0,2506 & 35,6888 & 0,5349 & 0,0517 & 0,0023 & 186,0 & 7,6 & 178,2 & 2,7 & 178,2 & 2,7 \\
\hline VM6-1_57 & 107,0 & 1,2 & 0,1900 & 0,0110 & 0,0281 & 0,0006 & 0,1817 & 35,6252 & 0,7234 & 0,0494 & 0,0029 & 174,7 & 9,3 & 178,4 & 3,6 & 178,4 & 3,6 \\
\hline VM6-1_83 & 117,8 & 0,9 & 0,2020 & 0,0110 & 0,0281 & 0,0005 & 0,2556 & 35,5872 & 0,6206 & 0,0525 & 0,0028 & 185,6 & 8,9 & 178,6 & 3,1 & 178,6 & 3,1 \\
\hline VM6-1_26 & 834,0 & 0,8 & 0,1920 & 0,0039 & 0,0281 & 0,0004 & 0,5290 & 35,5366 & 0,5178 & 0,0492 & 0,0009 & 178,2 & 3,3 & 178,9 & 2,6 & 178,9 & 2,6 \\
\hline VM6-1_15 & 591,0 & 1,1 & 0,1917 & 0,0044 & 0,0282 & 0,0005 & 0,3001 & 35,5114 & 0,5927 & 0,0498 & 0,0012 & 178,3 & 3,8 & 179,0 & 2,9 & 179,0 & 2,9 \\
\hline VM6-1_14 & 485,0 & 1,2 & 0,1860 & 0,0085 & 0,0282 & 0,0007 & 0,2601 & 35,4610 & 0,8551 & 0,0482 & 0,0024 & 173,7 & 7,5 & 179,2 & 4,3 & 179,2 & 4,3 \\
\hline VM6-1_80 & 1650,0 & 1,0 & 0,1885 & 0,0054 & 0,0282 & 0,0007 & 0,6946 & 35,4108 & 0,9279 & 0,0494 & 0,0011 & 175,2 & 4,6 & 179,5 & 4,7 & 179,5 & 4,7 \\
\hline VM6-1_93 & 469,0 & 1,2 & 0,1933 & 0,0078 & 0,0283 & 0,0006 & 0,2696 & 35,3982 & 0,7393 & 0,0494 & 0,0018 & 179,9 & 6,9 & 179,6 & 3,7 & 179,6 & 3,7 \\
\hline VM6-1_85 & 84,8 & 0,9 & 0,2250 & 0,0230 & 0,0283 & 0,0007 & 0,2855 & 35,3482 & 0,8996 & 0,0573 & 0,0051 & 203,0 & 18,0 & 179,8 & 4,5 & 179,8 & 4,5 \\
\hline VM6-1_10 & 490,0 & 1,4 & 0,1943 & 0,0053 & 0,0283 & 0,0005 & 0,2776 & 35,3357 & 0,5744 & 0,0500 & 0,0014 & 180,0 & 4,5 & 179,9 & 2,9 & 179,9 & 2,9 \\
\hline VM6-1_61 & 425,0 & 1,5 & 0,1930 & 0,0046 & 0,0283 & 0,0004 & 0,0963 & 35,3357 & 0,4620 & 0,0501 & 0,0014 & 178,9 & 3,9 & 179,9 & 2,3 & 179,9 & 2,3 \\
\hline VM6-1_87 & 898,0 & 2,3 & 0,2250 & 0,0150 & 0,0283 & 0,0006 & 0,3098 & 35,3357 & 0,7741 & 0,0592 & 0,0036 & 206,0 & 12,0 & 179,9 & 3,9 & 179,9 & 3,9 \\
\hline VM6-1_18 & 473,0 & 1,2 & 0,1956 & 0,0052 & 0,0284 & 0,0005 & 0,2275 & 35,1865 & 0,5943 & 0,0496 & 0,0015 & 181,1 & 4,4 & 180,7 & 3,0 & 180,7 & 3,0 \\
\hline VM6-1_70 & 134,0 & 1,1 & 0,1868 & 0,0097 & 0,0284 & 0,0005 & 0,0886 & 35,1617 & 0,6676 & 0,0472 & 0,0024 & 173,0 & 8,2 & 180,7 & 3,4 & 180,7 & 3,4 \\
\hline VM6-1_50 & 1014,0 & 0,7 & 0,2000 & 0,0038 & 0,0284 & 0,0004 & 0,5607 & 35,1617 & 0,5193 & 0,0512 & 0,0008 & 185,0 & 3,2 & 180,8 & 2,6 & 180,8 & 2,6 \\
\hline VM6-1_105 & 168,0 & 1,0 & 0,1987 & 0,0093 & 0,0286 & 0,0005 & 0,0483 & 34,9895 & 0,6611 & 0,0512 & 0,0026 & 183,9 & 8,1 & 181,6 & 3,4 & 181,6 & 3,4 \\
\hline VM6-1_72 & 603,0 & 0,7 & 0,2009 & 0,0041 & 0,0286 & 0,0003 & 0,1360 & 34,9528 & 0,3665 & 0,0511 & 0,0011 & 185,7 & 3,4 & 181,8 & 1,9 & 181,8 & 1,9 \\
\hline
\end{tabular}




\begin{tabular}{|c|c|c|c|c|c|c|c|c|c|c|c|c|c|c|c|c|c|}
\hline $\begin{array}{l}\text { Puntos de } \\
\text { análisis }\end{array}$ & $\begin{array}{c}\mathrm{U} \\
(\mathrm{ppm})\end{array}$ & $\begin{array}{l}\mathrm{U} / \\
\mathrm{Th}\end{array}$ & ${ }^{207} \mathrm{~Pb} /{ }^{235} \mathrm{U}$ & $\pm 2 \sigma$ & ${ }^{206} \mathrm{~Pb} /{ }^{238} \mathrm{U}$ & $\pm 2 \sigma$ & $\begin{array}{l}\text { Coeficiente } \\
\text { Correlación }\end{array}$ & ${ }^{238} \mathrm{U} /{ }^{206} \mathrm{~Pb}$ & $\pm 2 \sigma$ & ${ }^{207} \mathrm{~Pb} /{ }^{206} \mathrm{~Pb}$ & $\pm 2 \sigma$ & $\begin{array}{c}{ }^{207} \mathrm{~Pb} /{ }^{/ 25} \mathrm{U} \\
\mathrm{Ma}\end{array}$ & $\begin{array}{l} \pm 2 \sigma \\
\mathrm{Ma}\end{array}$ & $\begin{array}{c}{ }^{206} \mathrm{~Pb} /{ }^{238} \mathrm{U} \\
\mathrm{Ma}\end{array}$ & $\begin{array}{l} \pm 2 \sigma \\
\mathrm{Ma}\end{array}$ & $\begin{array}{c}\text { Best } \\
\text { Age } \\
\text { Ma }\end{array}$ & $\begin{array}{c}2 \sigma \\
\text { Abs } \\
\text { Error } \\
\text { Ma } \\
\end{array}$ \\
\hline VM6-1_67 & 109,0 & 1,7 & 0,2010 & 0,0120 & 0,0287 & 0,0006 & 0,2051 & 34,9040 & 0,7066 & 0,0512 & 0,0031 & 184,0 & 10,0 & 182,0 & 3,6 & 182,0 & 3,6 \\
\hline VM6-1_20 & 165,0 & 1,6 & 0,1929 & 0,0091 & 0,0287 & 0,0006 & 0,2171 & 34,8068 & 0,7633 & 0,0488 & 0,0023 & 178,3 & 7,7 & 182,6 & 4,0 & 182,6 & 4,0 \\
\hline VM6-1_100 & 137,0 & 1,3 & 0,2012 & 0,0085 & 0,0289 & 0,0006 & 0,1035 & 34,6500 & 0,7564 & 0,0513 & 0,0023 & 185,2 & 7,1 & 183,3 & 4,0 & 183,3 & 4,0 \\
\hline VM6-1_42 & 404,0 & 1,9 & 0,1970 & 0,0097 & 0,0289 & 0,0005 & 0,0001 & 34,6500 & 0,6363 & 0,0510 & 0,0027 & 182,4 & 8,3 & 183,4 & 3,3 & 183,4 & 3,3 \\
\hline VM6-1_6 & 47,6 & 1,3 & 0,2030 & 0,0210 & 0,0290 & 0,0010 & 0,0430 & 34,4353 & 1,1265 & 0,0520 & 0,0057 & 184,0 & 18,0 & 184,5 & 6,0 & 184,5 & 6,0 \\
\hline VM6-1_102 & 251,0 & 1,2 & 0,1949 & 0,0067 & 0,0292 & 0,0005 & 0,2442 & 34,2466 & 0,5630 & 0,0484 & 0,0016 & 180,3 & 5,7 & 185,5 & 3,0 & 185,5 & 3,0 \\
\hline VM6-1_40 & 243,0 & 1,1 & 0,2039 & 0,0080 & 0,0293 & 0,0004 & 0,2655 & 34,1181 & 0,5005 & 0,0503 & 0,0019 & 188,6 & 6,5 & 186,2 & 2,7 & 186,2 & 2,7 \\
\hline VM6-1_68 & 317,0 & 1,2 & 0,2042 & 0,0054 & 0,0294 & 0,0004 & 0,2762 & 34,0368 & 0,4286 & 0,0505 & 0,0013 & 188,3 & 4,5 & 186,6 & 2,3 & 186,6 & 2,3 \\
\hline VM6-1_79 & 556,0 & 3,2 & 0,2004 & 0,0044 & 0,0294 & 0,0004 & 0,3321 & 33,9905 & 0,4621 & 0,0493 & 0,0011 & 185,2 & 3,7 & 186,9 & 2,5 & 186,9 & 2,5 \\
\hline VM6-1_81 & 448,0 & 1,0 & 0,1995 & 0,0054 & 0,0295 & 0,0006 & 0,4459 & 33,8983 & 0,6435 & 0,0491 & 0,0013 & 184,3 & 4,6 & 187,4 & 3,5 & 187,4 & 3,5 \\
\hline VM6-1_89 & 155,0 & 1,2 & 0,2150 & 0,0098 & 0,0297 & 0,0005 & 0,0857 & 33,6474 & 0,5548 & 0,0528 & 0,0024 & 196,5 & 8,1 & 188,8 & 3,1 & 188,8 & 3,1 \\
\hline VM6-1_41 & 204,0 & 1,5 & 0,2011 & 0,0088 & 0,0299 & 0,0005 & 0,1372 & 33,4672 & 0,5936 & 0,0493 & 0,0023 & 185,3 & 7,5 & 189,7 & 3,3 & 189,7 & 3,3 \\
\hline VM6-1_64 & 100,0 & 1,3 & 0,2210 & 0,0160 & 0,0299 & 0,0008 & 0,0794 & 33,4560 & 0,9066 & 0,0545 & 0,0041 & 201,0 & 13,0 & 189,8 & 5,1 & 189,8 & 5,1 \\
\hline VM6-1_16 & 179,0 & 0,7 & 0,2146 & 0,0086 & 0,0300 & 0,0006 & 0,0467 & 33,3556 & 0,6119 & 0,0519 & 0,0022 & 196,8 & 7,2 & 190,4 & 3,5 & 190,4 & 3,5 \\
\hline VM6-1_97 & 820,0 & 2,2 & 0,2098 & 0,0084 & 0,0303 & 0,0008 & 0,3147 & 33,0142 & 0,8937 & 0,0505 & 0,0019 & 192,7 & 7,0 & 192,3 & 5,1 & 192,3 & 5,1 \\
\hline VM6-1_23 & 509,0 & 0,7 & 0,2111 & 0,0068 & 0,0306 & 0,0006 & 0,4069 & 32,6904 & 0,5985 & 0,0502 & 0,0015 & 194,0 & 5,7 & 194,2 & 3,5 & 194,2 & 3,5 \\
\hline VM6-1_33 & 90,8 & 0,8 & 0,2200 & 0,0140 & 0,0308 & 0,0006 & 0,0001 & 32,4781 & 0,6118 & 0,0522 & 0,0033 & 201,0 & 11,0 & 195,9 & 3,7 & 195,9 & 3,7 \\
\hline VM6-1_59 & 51,3 & 1,4 & 0,2000 & 0,0170 & 0,0310 & 0,0009 & 0,0451 & 32,2269 & 0,9763 & 0,0471 & 0,0043 & 183,0 & 14,0 & 196,9 & 5,9 & 196,9 & 5,9 \\
\hline VM6-1_73 & 190,0 & 0,9 & 0,2460 & 0,0120 & 0,0310 & 0,0007 & 0,2902 & 32,2373 & 0,7690 & 0,0580 & 0,0026 & 222,1 & 9,6 & 196,9 & 4,6 & 196,9 & 4,6 \\
\hline VM6-1_86 & 168,8 & 2,3 & 0,2197 & 0,0094 & 0,0311 & 0,0004 & 0,0032 & 32,1337 & 0,4337 & 0,0513 & 0,0023 & 200,8 & 7,8 & 197,5 & 2,6 & 197,5 & 2,6 \\
\hline VM6-1_98 & 233,0 & 0,7 & 0,2194 & 0,0090 & 0,0317 & 0,0006 & 0,0979 & 31,5457 & 0,5871 & 0,0500 & 0,0021 & 201,7 & 7,3 & 201,1 & 3,7 & 201,1 & 3,7 \\
\hline VM6-1_30 & 126,9 & 0,6 & 0,2460 & 0,0110 & 0,0341 & 0,0006 & 0,0217 & 29,2912 & 0,5148 & 0,0529 & 0,0026 & 222,4 & 9,2 & 216,4 & 3,7 & 216,4 & 3,7 \\
\hline
\end{tabular}




\begin{tabular}{|c|c|c|c|c|c|c|c|c|c|c|c|c|c|c|c|c|c|}
\hline $\begin{array}{l}\text { Puntos de } \\
\text { análisis }\end{array}$ & $\begin{array}{c}\mathrm{U} \\
(\mathrm{ppm})\end{array}$ & $\begin{array}{l}\mathrm{U} / \\
\mathrm{Th}\end{array}$ & ${ }^{207} \mathrm{~Pb} /{ }^{235} \mathrm{U}$ & $\pm 2 \sigma$ & ${ }^{206} \mathrm{~Pb} /{ }^{238} \mathrm{U}$ & $\pm 2 \sigma$ & $\begin{array}{l}\text { Coeficiente } \\
\text { Correlación }\end{array}$ & ${ }^{238} \mathrm{U} /{ }^{206} \mathrm{~Pb}$ & $\pm 2 \sigma$ & ${ }^{207} \mathrm{~Pb} /{ }^{206} \mathrm{~Pb}$ & $\pm 2 \sigma$ & $\begin{array}{c}{ }^{207} \mathrm{~Pb} /{ }^{235} \mathrm{U} \\
\mathrm{Ma}\end{array}$ & $\begin{array}{l} \pm 2 \sigma \\
\mathrm{Ma}\end{array}$ & $\begin{array}{c}{ }^{206} \mathrm{~Pb} /{ }^{238} \mathrm{U} \\
\mathrm{Ma}\end{array}$ & $\begin{array}{l} \pm 2 \sigma \\
\text { Ma }\end{array}$ & $\begin{array}{c}\text { Best } \\
\text { Age } \\
\text { Ma }\end{array}$ & $\begin{array}{c}2 \sigma \\
\text { Abs } \\
\text { Error } \\
\text { Ma }\end{array}$ \\
\hline VM6-2_1 & 103,2 & 1,2 & 0,1881 & 0,0130 & 0,0273 & 0,0005 & 0,0001 & 36,6032 & 0,6163 & 0,0500 & 0,0037 & 175,2 & 11,0 & 173,7 & 3,0 & 173,7 & 3,0 \\
\hline VM6-2_2 & 41,6 & 1,9 & 0,1800 & 0,0230 & 0,0276 & 0,0006 & 0,0978 & 36,2188 & 0,7871 & 0,0487 & 0,0064 & 161,0 & 19,0 & 175,5 & 3,8 & 175,5 & 3,8 \\
\hline VM6-2_3 & 64,7 & 1,7 & 0,2180 & 0,0180 & 0,0281 & 0,0005 & 0,1094 & 35,6252 & 0,5965 & 0,0566 & 0,0047 & 197,0 & 15,0 & 178,5 & 3,0 & 178,5 & 3,0 \\
\hline VM6-2_4 & 53,7 & 1,9 & 0,1810 & 0,0200 & 0,0292 & 0,0006 & 0,0490 & 34,3053 & 0,7414 & 0,0464 & 0,0052 & 164,0 & 17,0 & 185,2 & 4,0 & 185,2 & 4,0 \\
\hline VM6-2_5 & 173,4 & 4,1 & 0,2030 & 0,0140 & 0,0307 & 0,0005 & 0,0001 & 32,6158 & 0,5744 & 0,0489 & 0,0037 & 187,0 & 12,0 & 194,7 & 3,4 & 194,7 & 3,4 \\
\hline VM6-2_6 & 75,8 & 1,2 & 0,1920 & 0,0140 & 0,0281 & 0,0005 & 0,1719 & 35,5492 & 0,6066 & 0,0498 & 0,0037 & 176,0 & 12,0 & 178,8 & 3,0 & 178,8 & 3,0 \\
\hline VM6-2_7 & 544,3 & 1,6 & 0,1854 & 0,0056 & 0,0268 & 0,0004 & 0,4387 & 37,3832 & 0,5450 & 0,0503 & 0,0013 & 172,3 & 4,8 & 170,5 & 2,5 & 170,5 & 2,5 \\
\hline VM6-2_8 & 44,4 & 1,2 & 0,1670 & 0,0210 & 0,0279 & 0,0006 & 0,0215 & 35,8166 & 0,7697 & 0,0434 & 0,0054 & 151,0 & 18,0 & 177,5 & 3,8 & 177,5 & 3,8 \\
\hline VM6-2_9 & 53,7 & 1,9 & 0,2190 & 0,0320 & 0,0298 & 0,0008 & 0,0223 & 33,5909 & 0,8914 & 0,0552 & 0,0082 & 202,0 & 29,0 & 189,1 & 4,9 & 189,1 & 4,9 \\
\hline VM6-2_10 & 67,2 & 1,6 & 0,1970 & 0,0160 & 0,0281 & 0,0005 & 0,0001 & 35,6252 & 0,6346 & 0,0514 & 0,0043 & 179,0 & 14,0 & 178,4 & 3,1 & 178,4 & 3,1 \\
\hline VM6-2_11 & 596,2 & 0,9 & 0,1906 & 0,0048 & 0,0274 & 0,0003 & 0,2072 & 36,5497 & 0,4141 & 0,0506 & 0,0013 & 176,9 & 4,1 & 174,0 & 1,9 & 174,0 & 1,9 \\
\hline VM6-2_12 & 102,8 & 1,0 & 0,1920 & 0,0120 & 0,0278 & 0,0004 & 0,1186 & 36,0101 & 0,5446 & 0,0497 & 0,0030 & 176,0 & 10,0 & 176,6 & 2,6 & 176,6 & 2,6 \\
\hline VM6-2_13 & 163,6 & 1,3 & 0,2180 & 0,0170 & 0,0279 & 0,0005 & 0,3222 & 35,8423 & 0,6937 & 0,0566 & 0,0041 & 199,0 & 14,0 & 177,4 & 3,4 & 177,4 & 3,4 \\
\hline VM6-2_14 & 54,3 & 1,5 & 0,1940 & 0,0220 & 0,0278 & 0,0005 & 0,0546 & 35,9712 & 0,6858 & 0,0508 & 0,0059 & 175,0 & 19,0 & 176,8 & 3,3 & 176,8 & 3,3 \\
\hline VM6-2_15 & 808,9 & 1,8 & 0,2217 & 0,0067 & 0,0314 & 0,0005 & 0,3003 & 31,8471 & 0,5274 & 0,0512 & 0,0015 & 203,0 & 5,6 & 199,3 & 3,2 & 199,3 & 3,2 \\
\hline VM6-2_16 & 133,6 & 0,8 & 0,2110 & 0,0150 & 0,0305 & 0,0006 & 0,0680 & 32,7869 & 0,6557 & 0,0500 & 0,0037 & 193,0 & 13,0 & 193,6 & 3,8 & 193,6 & 3,8 \\
\hline VM6-2_17 & 37,5 & 1,8 & 0,3270 & 0,0420 & 0,0295 & 0,0007 & 0,2079 & 33,9328 & 0,8060 & 0,0773 & 0,0092 & 274,0 & 31,0 & 187,2 & 4,4 & 187,2 & 4,4 \\
\hline VM6-2_18 & 35,7 & 1,6 & 0,1870 & 0,0250 & 0,0276 & 0,0007 & 0,1166 & 36,2713 & 0,9078 & 0,0486 & 0,0066 & 169,0 & 21,0 & 175,3 & 4,3 & 175,3 & 4,3 \\
\hline VM6-2_19 & 104,9 & 1,8 & 0,2190 & 0,0350 & 0,0284 & 0,0014 & 0,0001 & 35,2113 & 1,7358 & 0,0566 & 0,0099 & 199,0 & 29,0 & 180,4 & 8,9 & 180,4 & 8,9 \\
\hline VM6-2_20 & 662,0 & 0,4 & 0,2321 & 0,0062 & 0,0276 & 0,0004 & 0,1699 & 36,2188 & 0,4985 & 0,0608 & 0,0017 & 211,5 & 5,1 & 175,5 & 2,4 & 175,5 & 2,4 \\
\hline VM6-2_21 & 57,1 & 1,3 & 0,2030 & 0,0270 & 0,0305 & 0,0009 & 0,0476 & 32,7761 & 0,9883 & 0,0482 & 0,0064 & 184,0 & 23,0 & 193,7 & 5,8 & 193,7 & 5,8 \\
\hline VM6-2_22 & 99,5 & 0,9 & 0,2050 & 0,0140 & 0,0275 & 0,0005 & 0,1482 & 36,3240 & 0,6333 & 0,0526 & 0,0035 & 187,0 & 12,0 & 175,0 & 3,0 & 175,0 & 3,0 \\
\hline VM6-2_23 & 110,1 & 1,6 & 0,2180 & 0,0230 & 0,0292 & 0,0007 & 0,1209 & 34,2583 & 0,8215 & 0,0553 & 0,0058 & 202,0 & 20,0 & 185,4 & 4,4 & 185,4 & 4,4 \\
\hline VM6-2_24 & 45,2 & 1,2 & 0,1900 & 0,0270 & 0,0278 & 0,0007 & 0,0755 & 35,9454 & 0,9432 & 0,0497 & 0,0072 & 174,0 & 24,0 & 176,9 & 4,6 & 176,9 & 4,6 \\
\hline VM6-2_25 & 335,9 & 1,2 & 0,2080 & 0,0100 & 0,0299 & 0,0005 & 0,2643 & 33,4113 & 0,5247 & 0,0503 & 0,0024 & 191,0 & 8,6 & 190,1 & 3,0 & 190,1 & 3,0 \\
\hline VM6-2_26 & 82,9 & 1,4 & 0,1900 & 0,0140 & 0,0287 & 0,0005 & 0,0428 & 34,8311 & 0,5945 & 0,0477 & 0,0036 & 174,0 & 12,0 & 182,4 & 3,0 & 182,4 & 3,0 \\
\hline VM6-2_27 & 357,5 & 1,5 & 0,2160 & 0,0150 & 0,0301 & 0,0011 & 0,1716 & 33,2226 & 1,2141 & 0,0522 & 0,0038 & 197,0 & 13,0 & 191,1 & 6,6 & 191,1 & 6,6 \\
\hline VM6-2_28 & 22,4 & 1,9 & 0,1660 & 0,0340 & 0,0276 & 0,0008 & 0,1737 & 36,2450 & 1,1035 & 0,0429 & 0,0087 & 144,0 & 29,0 & 175,4 & 5,3 & 175,4 & 5,3 \\
\hline VM6-2_29 & 113,4 & 1,3 & 0,2020 & 0,0140 & 0,0281 & 0,0004 & 0,1290 & 35,5872 & 0,5572 & 0,0521 & 0,0035 & 185,0 & 12,0 & 178,6 & 2,8 & 178,6 & 2,8 \\
\hline
\end{tabular}




\begin{tabular}{|c|c|c|c|c|c|c|c|c|c|c|c|c|c|c|c|c|c|}
\hline $\begin{array}{l}\text { Puntos de } \\
\text { análisis }\end{array}$ & $\begin{array}{c}\mathrm{U} \\
(\mathrm{ppm})\end{array}$ & $\begin{array}{l}\mathrm{U} / \\
\mathrm{Th}\end{array}$ & ${ }^{207} \mathrm{~Pb} /{ }^{235} \mathrm{U}$ & $\pm 2 \sigma$ & ${ }^{206} \mathrm{~Pb} /{ }^{238} \mathrm{U}$ & $\pm 2 \sigma$ & $\begin{array}{l}\text { Coeficiente } \\
\text { Correlación }\end{array}$ & ${ }^{238} \mathrm{U} /{ }^{206} \mathrm{~Pb}$ & $\pm 2 \sigma$ & ${ }^{207} \mathrm{~Pb} /{ }^{206} \mathrm{~Pb}$ & $\pm 2 \sigma$ & $\begin{array}{c}{ }^{207} \mathrm{~Pb} /{ }^{235} \mathrm{U} \\
\mathrm{Ma}\end{array}$ & $\begin{array}{l} \pm 2 \sigma \\
\mathrm{Ma}\end{array}$ & $\begin{array}{c}{ }^{206} \mathrm{~Pb} /{ }^{238} \mathrm{U} \\
\mathrm{Ma}\end{array}$ & $\begin{array}{l} \pm 2 \sigma \\
\mathrm{Ma}\end{array}$ & $\begin{array}{l}\text { Best } \\
\text { Age } \\
\text { Ma }\end{array}$ & $\begin{array}{c}2 \sigma \\
\text { Abs } \\
\text { Error } \\
\text { Ma } \\
\end{array}$ \\
\hline VM6-2_30 & 1315,4 & 0,4 & 0,1892 & 0,0043 & 0,0274 & 0,0003 & 0,2993 & 36,4830 & 0,3993 & 0,0501 & 0,0011 & 175,7 & 3,7 & 174,3 & 1,9 & 174,3 & 1,9 \\
\hline VM6-2_31 & 143,6 & 0,9 & 0,2130 & 0,0120 & 0,0300 & 0,0004 & 0,0215 & 33,3333 & 0,4889 & 0,0519 & 0,0030 & 195,0 & 9,9 & 190,6 & 2,8 & 190,6 & 2,8 \\
\hline VM6-2_32 & 43,4 & 1,5 & 0,1810 & 0,0230 & 0,0278 & 0,0006 & 0,0001 & 36,0360 & 0,7792 & 0,0477 & 0,0062 & 165,0 & 19,0 & 176,4 & 3,7 & 176,4 & 3,7 \\
\hline VM6-2_33 & 105,6 & 1,5 & 0,1930 & 0,0130 & 0,0289 & 0,0005 & 0,0500 & 34,5901 & 0,5384 & 0,0490 & 0,0035 & 179,0 & 12,0 & 183,7 & 2,8 & 183,7 & 2,8 \\
\hline VM6-2_34 & 98,9 & 1,9 & 0,1900 & 0,0150 & 0,0279 & 0,0005 & 0,0424 & 35,8423 & 0,6680 & 0,0503 & 0,0042 & 175,0 & 13,0 & 177,4 & 3,3 & 177,4 & 3,3 \\
\hline VM6-2_35 & 201,9 & 2,5 & 2,9810 & 0,0640 & 0,2368 & 0,0027 & 0,4502 & 4,2230 & 0,0482 & 0,0915 & 0,0018 & 1400,0 & 16,0 & 1370,0 & 14,0 & 1446,0 & 37,0 \\
\hline VM6-2_36 & 50,7 & 1,5 & 0,1740 & 0,0220 & 0,0280 & 0,0006 & 0,0391 & 35,6633 & 0,7758 & 0,0447 & 0,0059 & 157,0 & 20,0 & 178,2 & 3,8 & 178,2 & 3,8 \\
\hline VM6-2_37 & 57,3 & 2,2 & 0,2870 & 0,0360 & 0,0287 & 0,0007 & 0,2963 & 34,8311 & 0,8492 & 0,0727 & 0,0087 & 250,0 & 28,0 & 182,5 & 4,4 & 182,5 & 4,4 \\
\hline VM6-2_38 & 70,0 & 1,4 & 0,1810 & 0,0210 & 0,0282 & 0,0006 & 0,0428 & 35,4233 & 0,7654 & 0,0464 & 0,0054 & 164,0 & 18,0 & 179,4 & 3,8 & 179,4 & 3,8 \\
\hline VM6-2_39 & 95,8 & 1,8 & 0,2020 & 0,0200 & 0,0284 & 0,0007 & 0,0290 & 35,1741 & 0,8908 & 0,0535 & 0,0056 & 187,0 & 18,0 & 180,7 & 4,5 & 180,7 & 4,5 \\
\hline VM6-2_40 & 113,3 & 1,2 & 0,1800 & 0,0130 & 0,0273 & 0,0005 & 0,0689 & 36,5898 & 0,6560 & 0,0484 & 0,0036 & 166,0 & 11,0 & 173,8 & 3,0 & 173,8 & 3,0 \\
\hline VM6-2_41 & 122,3 & 1,0 & 0,2580 & 0,0170 & 0,0306 & 0,0004 & 0,2617 & 32,7332 & 0,4714 & 0,0611 & 0,0039 & 231,0 & 14,0 & 193,9 & 2,7 & 193,9 & 2,7 \\
\hline VM6-2_42 & 157,9 & 0,8 & 0,2150 & 0,0120 & 0,0309 & 0,0004 & 0,0332 & 32,3834 & 0,4404 & 0,0512 & 0,0029 & 197,0 & 10,0 & 196,1 & 2,6 & 196,1 & 2,6 \\
\hline VM6-2_43 & 75,7 & 1,0 & 0,2740 & 0,0230 & 0,0293 & 0,0006 & 0,0378 & 34,1647 & 0,7120 & 0,0691 & 0,0060 & 244,0 & 18,0 & 186,0 & 3,8 & 186,0 & 3,8 \\
\hline VM6-2_44 & 175,1 & 1,9 & 0,2010 & 0,0200 & 0,0281 & 0,0007 & 0,4103 & 35,5999 & 0,8998 & 0,0522 & 0,0047 & 184,0 & 16,0 & 178,6 & 4,4 & 178,6 & 4,4 \\
\hline VM6-2_45 & 106,5 & 1,0 & 0,1870 & 0,0200 & 0,0309 & 0,0007 & 0,0412 & 32,3625 & 0,7227 &, $04+3$ & 0,0048 & 172,0 & 17,0 & 196,1 & 4,3 & 196,1 & 4,3 \\
\hline VM6-2_46 & 92,0 & 0,9 & 0,1970 & 0,0300 & 0,0296 & 0,0008 & 0,0915 & 33,8410 & 0,9047 & 0,0491 & 0,0075 & 178,0 & 25,0 & 187,7 & 4,9 & 187,7 & 4,9 \\
\hline VM6-2_47 & 257,0 & 0,9 & 0,1886 & 0,0095 & 0,0282 & 0,0004 & 0,1549 & 35,5114 & 0,4540 & 0,0487 & 0,0024 & 174,2 & 8,0 & 179,0 & 2,3 & 179,0 & 2,3 \\
\hline VM6-2_48 & 177,4 & 0,9 & 0,2030 & 0,0160 & 0,0284 & 0,0005 & 0,1131 & 35,1989 & 0,6071 & 0,0518 & 0,0039 & 186,0 & 13,0 & 180,6 & 3,1 & 180,6 & 3,1 \\
\hline VM6-2_49 & 98,0 & 1,3 & 0,1810 & 0,0170 & 0,0275 & 0,0005 & 0,0001 & 36,3240 & 0,6597 & 0,0486 & 0,0044 & 166,0 & 14,0 & 175,1 & 3,1 & 175,1 & 3,1 \\
\hline VM6-2_50 & 239,9 & 2,1 & 0,2350 & 0,0110 & 0,0286 & 0,0004 & 0,0001 & 34,9162 & 0,4755 & 0,0605 & 0,0030 & 213,1 & 9,2 & 182,0 & 2,4 & 182,0 & 2,4 \\
\hline VM6-2_51 & 223,6 & 2,1 & 0,2190 & 0,0140 & 0,0316 & 0,0008 & 0,1792 & 31,6456 & 0,7711 & 0,0517 & 0,0034 & 202,0 & 12,0 & 200,5 & 4,8 & 200,5 & 4,8 \\
\hline VM6-2_52 & 128,6 & 1,4 & 0,1890 & 0,0140 & 0,0273 & 0,0005 & 0,0909 & 36,6569 & 0,6584 & 0,0501 & 0,0036 & 175,0 & 11,0 & 173,5 & 3,1 & 173,5 & 3,1 \\
\hline VM6-2_53 & 59,1 & 1,2 & 0,1830 & 0,0210 & 0,0269 & 0,0006 & 0,0001 & 37,2024 & 0,7889 & 0,0507 & 0,0060 & 165,0 & 18,0 & 171,0 & 3,6 & 171,0 & 3,6 \\
\hline VM6-2_54 & 162,0 & 1,1 & 0,2190 & 0,0140 & 0,0274 & 0,0006 & 0,0001 & 36,5364 & 0,7742 & 0,0590 & 0,0041 & 199,0 & 12,0 & 174,1 & 3,6 & 174,1 & 3,6 \\
\hline VM6-2_55 & 437,4 & 1,1 & 0,1824 & 0,0082 & 0,0270 & 0,0004 & 0,2706 & 37,0096 & 0,6027 & 0,0494 & 0,0022 & 169,6 & 7,0 & 171,9 & 2,8 & 171,9 & 2,8 \\
\hline VM6-2_56 & 72,6 & 1,8 & 0,1900 & 0,0210 & 0,0274 & 0,0005 & 0,0324 & 36,5097 & 0,7198 & 0,0517 & 0,0060 & 176,0 & 19,0 & 174,2 & 3,4 & 174,2 & 3,4 \\
\hline VM6-2_57 & 130,9 & 1,2 & 0,3030 & 0,0230 & 0,0295 & 0,0005 & 0,4838 & 33,9213 & 0,6098 & 0,0756 & 0,0057 & 264,0 & 18,0 & 187,3 & 3,3 & 187,3 & 3,3 \\
\hline VM6-2_58 & 91,4 & 1,1 & 0,1850 & 0,0160 & 0,0280 & 0,0006 & 0,0004 & 35,7654 & 0,7419 & 0,0490 & 0,0044 & 169,0 & 14,0 & 177,7 & 3,6 & 177,7 & 3,6 \\
\hline VM6-2_59 & 136,1 & 1,8 & 0,2420 & 0,0160 & 0,0342 & 0,0007 & 0,0582 & 29,2826 & 0,5574 & 0,0511 & 0,0032 & 217,0 & 13,0 & 216,4 & 4,1 & 216,4 & 4,1 \\
\hline VM6-2_60 & 119,4 & 1,4 & 0,2110 & 0,0220 & 0,0273 & 0,0007 & 0,0001 & 36,6166 & 0,9788 & 0,0558 & 0,0059 & 195,0 & 19,0 & 173,6 & 4,6 & 173,6 & 4,6 \\
\hline
\end{tabular}




\begin{tabular}{|c|c|c|c|c|c|c|c|c|c|c|c|c|c|c|c|c|c|}
\hline $\begin{array}{l}\text { Puntos de } \\
\text { análisis }\end{array}$ & $\begin{array}{c}\mathrm{U} \\
(\mathrm{ppm})\end{array}$ & $\begin{array}{l}\mathrm{U} / \\
\mathrm{Th}\end{array}$ & ${ }^{207} \mathrm{~Pb} /{ }^{235} \mathrm{U}$ & $\pm 2 \sigma$ & ${ }^{206} \mathrm{~Pb} /{ }^{238} \mathrm{U}$ & $\pm 2 \sigma$ & $\begin{array}{l}\text { Coeficiente } \\
\text { Correlación }\end{array}$ & ${ }^{238} \mathrm{U} /{ }^{206} \mathrm{~Pb}$ & $\pm 2 \sigma$ & ${ }^{207} \mathrm{~Pb} /{ }^{206} \mathrm{~Pb}$ & $\pm 2 \sigma$ & $\begin{array}{c}{ }^{207} \mathrm{~Pb} /{ }^{235} \mathrm{U} \\
\mathrm{Ma}\end{array}$ & $\begin{array}{l} \pm 2 \sigma \\
\mathrm{Ma}\end{array}$ & $\begin{array}{c}{ }^{206} \mathrm{~Pb} /{ }^{238} \mathrm{U} \\
\mathrm{Ma}\end{array}$ & $\begin{array}{l} \pm 2 \sigma \\
\mathrm{Ma}\end{array}$ & $\begin{array}{c}\text { Best } \\
\text { Age } \\
\text { Ma }\end{array}$ & $\begin{array}{c}2 \sigma \\
\text { Abs } \\
\text { Error } \\
\text { Ma }\end{array}$ \\
\hline VM6-2_61 & 236,0 & 1,0 & 0,1887 & 0,0099 & 0,0275 & 0,0005 & 0,0424 & 36,4299 & 0,5972 & 0,0505 & 0,0028 & 174,6 & 8,5 & 174,6 & 2,8 & 174,6 & 2,8 \\
\hline VM6-2_62 & 84,1 & 2,2 & 0,2230 & 0,0230 & 0,0317 & 0,0009 & 0,0654 & 31,5856 & 0,8580 & 0,0520 & 0,0054 & 200,0 & 19,0 & 200,9 & 5,4 & 200,9 & 5,4 \\
\hline VM6-2_63 & 72,6 & 1,8 & 0,3500 & 0,0390 & 0,0326 & 0,0008 & 0,4106 & 30,6843 & 0,7061 & 0,0765 & 0,0078 & 291,0 & 28,0 & 207,3 & 4,8 & 207,3 & 4,8 \\
\hline VM6-2_64 & 94,5 & 1,6 & 0,1970 & 0,0150 & 0,0279 & 0,0005 & 0,0781 & 35,8552 & 0,6557 & 0,0517 & 0,0042 & 179,0 & 13,0 & 177,3 & 3,2 & 177,3 & 3,2 \\
\hline VM6-2_65 & 64,0 & 1,9 & 0,1790 & 0,0230 & 0,0277 & 0,0006 & 0,0001 & 36,0750 & 0,7418 & 0,0478 & 0,0062 & 169,0 & 20,0 & 176,2 & 3,6 & 176,2 & 3,6 \\
\hline VM6-2_66 & 154,4 & 1,3 & 0,2380 & 0,0210 & 0,0326 & 0,0009 & 0,3477 & 30,6937 & 0,8856 & 0,0538 & 0,0043 & 215,0 & 17,0 & 206,6 & 5,8 & 206,6 & 5,8 \\
\hline VM6-2_67 & 168,2 & 1,6 & 0,3340 & 0,0480 & 0,0279 & 0,0012 & 0,3289 & 35,8423 & 1,5416 & 0,0841 & 0,0098 & 288,0 & 35,0 & 177,4 & 7,8 & 177,4 & 7,8 \\
\hline VM6-2_68 & 125,5 & 1,3 & 0,2080 & 0,0160 & 0,0302 & 0,0006 & 0,0662 & 33,1236 & 0,6254 & 0,0506 & 0,0040 & 189,0 & 13,0 & 191,7 & 3,6 & 191,7 & 3,6 \\
\hline VM6-2_69 & 83,2 & 1,9 & 0,3200 & 0,0390 & 0,0305 & 0,0009 & 0,2031 & 32,8407 & 0,9383 & 0,0777 & 0,0093 & 273,0 & 28,0 & 193,3 & 5,4 & 193,3 & 5,4 \\
\hline VM6-2_70 & 472,3 & 2,2 & 0,2080 & 0,0100 & 0,0294 & 0,0006 & 0,3730 & 34,0136 & 0,6594 & 0,0518 & 0,0023 & 191,2 & 8,4 & 186,8 & 3,6 & 186,8 & 3,6 \\
\hline VM6-2_71 & 173,8 & 1,0 & 0,1910 & 0,0120 & 0,0278 & 0,0004 & 0,0853 & 35,9971 & 0,5572 & 0,0500 & 0,0031 & 176,0 & 10,0 & 176,6 & 2,7 & 176,6 & 2,7 \\
\hline VM6-2_72 & 183,2 & 1,6 & 1,5230 & 0,0360 & 0,1538 & 0,0019 & 0,3277 & 6,5020 & 0,0803 & 0,0725 & 0,0017 & 936,0 & 15,0 & 923,0 & 10,0 & 923,0 & 10,0 \\
\hline VM6-2_73 & 109,7 & 1,3 & 0,1620 & 0,0290 & 0,0278 & 0,0009 & 0,0001 & 36,0360 & 1,1038 & 0,0431 & 0,0080 & 149,0 & 26,0 & 176,4 & 5,3 & 176,4 & 5,3 \\
\hline VM6-2_74 & 141,9 & 0,9 & 0,2060 & 0,0190 & 0,0263 & 0,0007 & 0,0777 & 38,0228 & 1,0409 & 0,0577 & 0,0053 & 188,0 & 16,0 & 167,3 & 4,5 & 167,3 & 4,5 \\
\hline VM6-2_75 & 149,8 & 0,7 & 0,1870 & 0,0120 & 0,0274 & 0,0004 & 0,0665 & 36,5097 & 0,5332 & 0,0495 & 0,0032 & 172,0 & 10,0 & 174,2 & 2,5 & 174,2 & 2,5 \\
\hline VM6-2_76 & 139,0 & 1,4 & 0,2530 & 0,0210 & 0,0311 & 0,0007 & 0,3662 & 32,1958 & 0,7567 & 0,0595 & 0,0046 & 229,0 & 18,0 & 197,1 & 4,5 & 197,1 & 4,5 \\
\hline VM6-2_77 & 102,6 & 1,4 & 0,1930 & 0,0140 & 0,0277 & 0,0005 & 0,1209 & 36,1402 & 0,6139 & 0,0514 & 0,0039 & 178,0 & 12,0 & 175,9 & 3,0 & 175,9 & 3,0 \\
\hline VM6-2_78 & 146,9 & 2,2 & 1,8790 & 0,0500 & 0,1639 & 0,0022 & 0,2971 & 6,1013 & 0,0819 & 0,0835 & 0,0022 & 1071,0 & 18,0 & 978,0 & 12,0 & 978,0 & 12,0 \\
\hline VM6-2_79 & 78,0 & 3,4 & 2,7310 & 0,0840 & 0,2270 & 0,0042 & 0,4157 & 4,4053 & 0,0815 & 0,0876 & 0,0024 & 1331,0 & 23,0 & 1318,0 & 22,0 & 1353,0 & 54,0 \\
\hline VM6-2_80 & 518,9 & 1,4 & 1,4960 & 0,0300 & 0,1412 & 0,0022 & 0,5347 & 7,0822 & 0,1103 & 0,0776 & 0,0014 & 927,0 & 12,0 & 851,0 & 12,0 & 851,0 & 12,0 \\
\hline VM6-2_81 & 190,8 & 1,7 & 0,2070 & 0,0130 & 0,0293 & 0,0006 & 0,0335 & 34,1530 & 0,6415 & 0,0519 & 0,0034 & 190,0 & 11,0 & 186,0 & 3,4 & 186,0 & 3,4 \\
\hline VM6-2_82 & 204,0 & 1,3 & 0,2034 & 0,0099 & 0,0288 & 0,0004 & 0,1573 & 34,7343 & 0,5067 & 0,0517 & 0,0025 & 186,7 & 8,3 & 183,0 & 2,7 & 183,0 & 2,7 \\
\hline VM6-2_83 & 584,3 & 1,5 & 0,1900 & 0,0067 & 0,0278 & 0,0003 & 0,2741 & 35,9195 & 0,4387 & 0,0502 & 0,0018 & 176,0 & 5,7 & 177,0 & 2,2 & 177,0 & 2,2 \\
\hline VM6-2_84 & 157,4 & 1,2 & 0,1830 & 0,0140 & 0,0273 & 0,0006 & 0,1333 & 36,5898 & 0,7899 & 0,0491 & 0,0038 & 171,0 & 13,0 & 173,8 & 3,7 & 173,8 & 3,7 \\
\hline VM6-2_85 & 154,4 & 1,6 & 0,4500 & 0,0450 & 0,0339 & 0,0008 & 0,1708 & 29,4638 & 0,7119 & 0,0975 & 0,0099 & 366,0 & 31,0 & 215,1 & 5,1 & 215,1 & 5,1 \\
\hline VM6-2_86 & 170,7 & 1,0 & 0,1840 & 0,0140 & 0,0268 & 0,0005 & 0,1205 & 37,2856 & 0,6812 & 0,0500 & 0,0037 & 172,0 & 11,0 & 170,6 & 3,1 & 170,6 & 3,1 \\
\hline VM6-2_87 & 105,1 & 1,0 & 0,1910 & 0,0160 & 0,0276 & 0,0005 & 0,0001 & 36,2976 & 0,6061 & 0,0512 & 0,0043 & 175,0 & 13,0 & 175,2 & 2,9 & 175,2 & 2,9 \\
\hline VM6-2_88 & 105,5 & 1,5 & 0,2010 & 0,0200 & 0,0283 & 0,0005 & 0,1086 & 35,3482 & 0,6372 & 0,0532 & 0,0050 & 186,0 & 17,0 & 179,8 & 3,2 & 179,8 & 3,2 \\
\hline VM6-2_89 & 230,0 & 1,9 & 0,2090 & 0,0140 & 0,0324 & 0,0006 & 0,1148 & 30,8833 & 0,5818 & 0,0469 & 0,0030 & 191,0 & 12,0 & 205,4 & 3,8 & 205,4 & 3,8 \\
\hline VM6-2_90 & 154,8 & 1,0 & 0,2130 & 0,0140 & 0,0300 & 0,0004 & 0,0999 & 33,3222 & 0,4775 & 0,0524 & 0,0036 & 195,0 & 12,0 & 190,6 & 2,7 & 190,6 & 2,7 \\
\hline VM6-2_91 & 413,6 & 0,8 & 0,1821 & 0,0073 & 0,0275 & 0,0004 & 0,1029 & 36,3504 & 0,5021 & 0,0484 & 0,0020 & 169,2 & 6,3 & 175,0 & 2,4 & 175,0 & 2,4 \\
\hline
\end{tabular}




\begin{tabular}{|c|c|c|c|c|c|c|c|c|c|c|c|c|c|c|c|c|c|}
\hline $\begin{array}{l}\text { Puntos de } \\
\text { análisis }\end{array}$ & $\begin{array}{c}\mathrm{U} \\
(\mathrm{ppm})\end{array}$ & $\begin{array}{l}\text { U/ } \\
\text { Th }\end{array}$ & ${ }^{207} \mathrm{~Pb} /{ }^{235} \mathrm{U}$ & $\pm 2 \sigma$ & ${ }^{206} \mathrm{~Pb} /{ }^{238} \mathrm{U}$ & $\pm 2 \sigma$ & $\begin{array}{l}\text { Coeficiente } \\
\text { Correlación }\end{array}$ & ${ }^{238} \mathrm{U} /{ }^{206} \mathrm{~Pb}$ & $\pm 2 \sigma$ & ${ }^{207} \mathrm{~Pb} /{ }^{206} \mathrm{~Pb}$ & $\pm 2 \sigma$ & $\begin{array}{c}{ }^{207} \mathrm{~Pb} /{ }^{235} \mathrm{U} \\
\mathrm{Ma}\end{array}$ & $\begin{array}{l} \pm 2 \sigma \\
\mathrm{Ma}\end{array}$ & $\begin{array}{c}{ }^{206} \mathrm{~Pb} /{ }^{238} \mathrm{U} \\
\mathrm{Ma}\end{array}$ & $\begin{array}{l} \pm 2 \sigma \\
\mathrm{Ma}\end{array}$ & $\begin{array}{c}\text { Best } \\
\text { Age } \\
\text { Ma }\end{array}$ & $\begin{array}{c}2 \sigma \\
\text { Abs } \\
\text { Error } \\
\text { Ma }\end{array}$ \\
\hline VM6-2_92 & 41,1 & 1,6 & 0,1800 & 0,0350 & 0,0287 & 0,0008 & 0,0159 & 34,8554 & 0,9962 & 0,0471 & 0,0094 & 157,0 & 30,0 & 182,3 & 5,1 & 182,3 & 5,1 \\
\hline VM6-2_93 & 24,8 & 1,4 & 0,1540 & 0,0480 & 0,0280 & 0,0011 & 0,1273 & 35,7143 & 1,4031 & 0,0420 & 0,0120 & 128,0 & 45,0 & 178,0 & 6,7 & 178,0 & 6,7 \\
\hline VM6-2_94 & 174,6 & 1,2 & 0,2020 & 0,0200 & 0,0270 & 0,0006 & 0,1798 & 37,0645 & 0,8655 & 0,0547 & 0,0051 & 184,0 & 17,0 & 171,6 & 4,0 & 171,6 & 4,0 \\
\hline VM6-2_95 & 43,0 & 1,5 & 0,1670 & 0,0320 & 0,0274 & 0,0008 & 0,0999 & 36,5097 & 1,0530 & 0,0450 & 0,0087 & 144,0 & 28,0 & 174,1 & 5,0 & 174,1 & 5,0 \\
\hline VM6-2_96 & 56,6 & 1,1 & 0,2180 & 0,0280 & 0,0275 & 0,0006 & 0,1319 & 36,4034 & 0,8349 & 0,0583 & 0,0074 & 196,0 & 22,0 & 174,6 & 3,9 & 174,6 & 3,9 \\
\hline VM6-2_97 & 509,8 & 1,2 & 0,2101 & 0,0084 & 0,0302 & 0,0004 & 0,2792 & 33,1236 & 0,4389 & 0,0513 & 0,0021 & 192,9 & 7,1 & 191,7 & 2,5 & 191,7 & 2,5 \\
\hline VM6-2_98 & 365,0 & 1,2 & 0,1865 & 0,0084 & 0,0273 & 0,0004 & 0,1151 & 36,6569 & 0,4837 & 0,0499 & 0,0023 & 172,7 & 7,1 & 173,5 & 2,3 & 173,5 & 2,3 \\
\hline VM6-2_99 & 109,4 & 1,6 & 0,2550 & 0,0260 & 0,0287 & 0,0007 & 0,3328 & 34,9040 & 0,8406 & 0,0645 & 0,0062 & 225,0 & 21,0 & 182,0 & 4,3 & 182,0 & 4,3 \\
\hline VM6-2_100 & 101,8 & 1,7 & 0,1860 & 0,0160 & 0,0234 & 0,0004 & 0,0001 & 42,7350 & 0,6940 & 0,0582 & 0,0052 & 171,0 & 14,0 & 149,1 & 2,4 & 149,1 & 2,4 \\
\hline VM6-2_101 & 232,0 & 1,1 & 0,2020 & 0,0130 & 0,0268 & 0,0005 & 0,0001 & 37,3413 & 0,6275 & 0,0551 & 0,0035 & 185,0 & 11,0 & 170,3 & 2,8 & 170,3 & 2,8 \\
\hline VM6-2_102 & 117,8 & 1,9 & 0,2070 & 0,0170 & 0,0287 & 0,0005 & 0,0497 & 34,9040 & 0,6457 & 0,0530 & 0,0044 & 188,0 & 14,0 & 182,0 & 3,3 & 182,0 & 3,3 \\
\hline VM6-2_103 & 60,5 & 2,1 & 0,2150 & 0,0340 & 0,0286 & 0,0010 & 0,2077 & 34,9773 & 1,1989 & 0,0549 & 0,0089 & 190,0 & 29,0 & 181,7 & 6,1 & 181,7 & 6,1 \\
\hline VM6-2_104 & 305,2 & 2,5 & 1,6610 & 0,0330 & 0,1644 & 0,0024 & 0,1716 & 6,0827 & 0,0888 & 0,0732 & 0,0016 & 992,0 & 12,0 & 981,0 & 13,0 & 981,0 & 13,0 \\
\hline VM6-2_105 & 111,8 & 1,5 & 0,2410 & 0,0210 & 0,0300 & 0,0006 & 0,2848 & 33,3556 & 0,6898 & 0,0583 & 0,0047 & 215,0 & 17,0 & 190,4 & 3,9 & 190,4 & 3,9 \\
\hline VM6-2_106 & 75,8 & 1,3 & 0,1880 & 0,0200 & 0,0277 & 0,0006 & 0,0874 & 36,1272 & 0,7178 & 0,0513 & 0,0057 & 175,0 & 18,0 & 176,0 & 3,4 & 176,0 & 3,4 \\
\hline VM6-2_107 & 150,6 & 1,2 & 0,1970 & 0,0140 & 0,0273 & 0,0005 & 0,1163 & 36,6300 & 0,6172 & 0,0528 & 0,0037 & 181,0 & 12,0 & 173,6 & 2,9 & 173,6 & 2,9 \\
\hline VM6-2_108 & 182,2 & 2,4 & 1,0560 & 0,0220 & 0,1072 & 0,0013 & 0,2050 & 9,3284 & 0,1131 & 0,0719 & 0,0016 & 731,0 & 11,0 & 656,3 & 7,3 & 656,3 & 7,3 \\
\hline VM6-2_109 & 189,0 & 1,2 & 0,2060 & 0,0160 & 0,0296 & 0,0005 & 0,0001 & 33,7496 & 0,5695 & 0,0509 & 0,0041 & 188,0 & 13,0 & 188,2 & 3,1 & 188,2 & 3,1 \\
\hline VM6-2_110 & 101,7 & 1,5 & 0,1780 & 0,0170 & 0,0274 & 0,0006 & 0,1636 & 36,4432 & 0,7305 & 0,0464 & 0,0045 & 162,0 & 15,0 & 174,5 & 3,5 & 174,5 & 3,5 \\
\hline VM6-2_111 & 72,7 & 1,3 & 0,1880 & 0,0220 & 0,0279 & 0,0006 & 0,0001 & 35,7910 & 0,7430 & 0,0505 & 0,0060 & 171,0 & 19,0 & 177,6 & 3,6 & 177,6 & 3,6 \\
\hline VM6-2_112 & 248,2 & 2,1 & 0,2020 & 0,0100 & 0,0274 & 0,0004 & 0,2179 & 36,4564 & 0,5715 & 0,0541 & 0,0028 & 186,1 & 8,7 & 174,4 & 2,7 & 174,4 & 2,7 \\
\hline VM6-2_113 & 118,2 & 1,1 & 0,1890 & 0,0150 & 0,0273 & 0,0005 & 0,2197 & 36,5764 & 0,6555 & 0,0506 & 0,0041 & 175,0 & 13,0 & 173,8 & 3,1 & 173,8 & 3,1 \\
\hline VM6-2_114 & 545,4 & 2,5 & 0,1983 & 0,0073 & 0,0289 & 0,0004 & 0,1412 & 34,6621 & 0,4566 & 0,0497 & 0,0019 & 183,1 & 6,2 & 183,3 & 2,4 & 183,3 & 2,4 \\
\hline VM6-2_115 & 440,0 & 5,0 & 2,4830 & 0,0490 & 0,2043 & 0,0030 & 0,7220 & 4,8948 & 0,0719 & 0,0881 & 0,0013 & 1266,0 & 14,0 & 1198,0 & 16,0 & 1198,0 & 16,0 \\
\hline VM6-2_116 & 613,4 & 1,4 & 0,1894 & 0,0061 & 0,0281 & 0,0004 & 0,1006 & 35,5745 & 0,4429 & 0,0492 & 0,0017 & 175,7 & 5,2 & 178,7 & 2,2 & 178,7 & 2,2 \\
\hline VM6-2_117 & 70,4 & 2,2 & 0,1950 & 0,0260 & 0,0277 & 0,0007 & 0,0497 & 36,0620 & 0,9103 & 0,0514 & 0,0070 & 175,0 & 23,0 & 176,3 & 4,4 & 176,3 & 4,4 \\
\hline VM6-2_118 & 274,8 & 1,3 & 0,1920 & 0,0110 & 0,0278 & 0,0004 & 0,2728 & 35,9842 & 0,5568 & 0,0498 & 0,0027 & 178,5 & 9,3 & 176,7 & 2,7 & 176,7 & 2,7 \\
\hline
\end{tabular}




\begin{tabular}{|c|c|c|c|c|c|c|c|c|c|c|c|c|c|c|c|c|c|}
\hline $\begin{array}{l}\text { Puntos de } \\
\text { análisis }\end{array}$ & $\begin{array}{c}\mathrm{U} \\
(\mathrm{ppm})\end{array}$ & $\mathrm{U} / \mathrm{Th}$ & ${ }^{207} \mathrm{~Pb} /{ }^{235} \mathrm{U}$ & $\pm 2 \sigma$ & ${ }^{206} \mathrm{~Pb} /{ }^{238} \mathrm{U}$ & $\pm 2 \sigma$ & $\begin{array}{l}\text { Coeficiente } \\
\text { Correlación }\end{array}$ & ${ }^{238} \mathrm{U} /{ }^{206} \mathrm{~Pb}$ & $\pm 2 \sigma$ & ${ }^{207} \mathrm{~Pb} /{ }^{206} \mathrm{~Pb}$ & $\pm 2 \sigma$ & $\begin{array}{c}{ }^{207} \mathrm{~Pb} /{ }^{235} \mathrm{U} \\
\mathrm{Ma}\end{array}$ & $\begin{array}{l} \pm 2 \sigma \\
\mathrm{Ma}\end{array}$ & $\begin{array}{c}{ }^{206} \mathrm{~Pb} /{ }^{238} \mathrm{U} \\
\mathrm{Ma}\end{array}$ & $\begin{array}{l} \pm 2 \sigma \\
\mathrm{Ma}\end{array}$ & $\begin{array}{l}\text { Best } \\
\text { Age } \\
\text { Ma }\end{array}$ & $\begin{array}{c}2 \sigma \\
\text { Abs } \\
\text { Error } \\
\text { Ma }\end{array}$ \\
\hline VM1_1 & 110,0 & 0,9 & 0,2300 & 0,0110 & 0,0309 & 0,0005 & 0,0001 & 32,4149 & 0,5359 & 0,0549 & 0,0028 & 209,2 & 8,6 & 195,8 & 3,2 & 195,8 & 3,2 \\
\hline VM1_2 & 156,0 & 1,1 & 0,2200 & 0,0110 & 0,0307 & 0,0005 & 0,1834 & 32,6158 & 0,4893 & 0,0518 & 0,0025 & 201,2 & 9,0 & 194,7 & 2,9 & 194,7 & 2,9 \\
\hline VM1_3 & 702,0 & 3,0 & 1,7030 & 0,0160 & 0,1699 & 0,0017 & 0,5180 & 5,8858 & 0,0589 & 0,0726 & 0,0007 & 1009,1 & 5,9 & 1011,3 & 9,5 & 997,0 & 18,0 \\
\hline VM1_4 & 149,5 & 1,0 & 3,4470 & 0,0390 & 0,2655 & 0,0022 & 0,4196 & 3,7665 & 0,0312 & 0,0935 & 0,0011 & 1514,1 & 9,0 & 1518,0 & 11,0 & 1493,0 & 22,0 \\
\hline VM1_5 & 1361,0 & 1,9 & 0,5369 & 0,0063 & 0,0700 & 0,0006 & 0,6216 & 14,2959 & 0,1308 & 0,0559 & 0,0005 & 436,0 & 4,2 & 435,8 & 3,8 & 435,8 & 3,8 \\
\hline VM1_6 & 365,0 & 1,7 & 1,4370 & 0,0390 & 0,1499 & 0,0040 & 0,8943 & 6,6711 & 0,1780 & 0,0697 & 0,0008 & 900,0 & 16,0 & 899,0 & 22,0 & 912,0 & 24,0 \\
\hline VM1_7 & 270,0 & 2,3 & 1,9660 & 0,0220 & 0,1867 & 0,0014 & 0,3399 & 5,3562 & 0,0402 & 0,0764 & 0,0008 & 1103,0 & 7,3 & 1103,1 & 7,4 & 1100,0 & 21,0 \\
\hline VM1_8 & 278,0 & 1,0 & 0,2145 & 0,0062 & 0,0297 & 0,0004 & 0,0971 & 33,6927 & 0,4087 & 0,0527 & 0,0016 & 197,7 & 5,0 & 188,5 & 2,2 & 188,5 & 2,2 \\
\hline VM1_9 & 762,0 & 1,5 & 1,6700 & 0,0180 & 0,1666 & 0,0018 & 0,4452 & 6,0024 & 0,0649 & 0,0730 & 0,0008 & 996,7 & 6,7 & 993,0 & 10,0 & 1008,0 & 21,0 \\
\hline VM1_10 & 402,0 & 2,3 & 2,6500 & 0,0380 & 0,2267 & 0,0024 & 0,7375 & 4,4111 & 0,0467 & 0,0846 & 0,0008 & 1313,0 & 11,0 & 1317,0 & 13,0 & 1304,0 & 18,0 \\
\hline VM1_11 & 743,0 & 0,8 & 1,5350 & 0,0550 & 0,1358 & 0,0054 & 0,9525 & 7,3638 & 0,2928 & 0,0816 & 0,0010 & 940,0 & 22,0 & 819,0 & 31,0 & 1235,0 & 22,0 \\
\hline VM1_12 & 687,0 & 4,1 & 1,6370 & 0,0130 & 0,1652 & 0,0010 & 0,4017 & 6,0533 & 0,0366 & 0,0719 & 0,0005 & 984,2 & 5,0 & 985,4 & 5,7 & 980,0 & 15,0 \\
\hline VM1_13 & 72,7 & 1,7 & 0,2110 & 0,0150 & 0,0300 & 0,0007 & 0,2268 & 33,3111 & 0,7545 & 0,0515 & 0,0038 & 192,0 & 13,0 & 190,6 & 4,3 & 190,6 & 4,3 \\
\hline VM1_14 & 166,0 & 1,2 & 0,2940 & 0,0150 & 0,0310 & 0,0005 & 0,3574 & 32,2581 & 0,4787 & 0,0683 & 0,0031 & 261,0 & 12,0 & 196,8 & 2,8 & 196,8 & 2,8 \\
\hline VM1_15 & 115,5 & 1,2 & 1,7390 & 0,0300 & 0,1710 & 0,0018 & 0,2547 & 5,8480 & 0,0616 & 0,0733 & 0,0013 & 1021,0 & 11,0 & 1017,3 & 9,8 & 1009,0 & 37,0 \\
\hline VM1_16 & 36,6 & 0,7 & 0,2110 & 0,0230 & 0,0301 & 0,0007 & 0,0001 & 33,2557 & 0,8073 & 0,0521 & 0,0058 & 189,0 & 19,0 & 191,0 & 4,6 & 191,0 & 4,6 \\
\hline VM1_17 & 759,0 & 1,3 & 0,2887 & 0,0046 & 0,0404 & 0,0004 & 0,3171 & 24,7280 & 0,2140 & 0,0513 & 0,0007 & 257,8 & 3,7 & 255,5 & 2,1 & 255,5 & 2,1 \\
\hline VM1_18 & 127,4 & 0,9 & 0,2213 & 0,0094 & 0,0297 & 0,0004 & 0,0997 & 33,6587 & 0,4192 & 0,0543 & 0,0024 & 202,0 & 7,8 & 188,7 & 2,3 & 188,7 & 2,3 \\
\hline VM1_19 & 150,2 & 0,9 & 0,2430 & 0,0110 & 0,0298 & 0,0005 & 0,1403 & 33,5233 & 0,5282 & 0,0592 & 0,0027 & 220,1 & 8,8 & 189,4 & 3,0 & 189,4 & 3,0 \\
\hline VM1_20 & 129,1 & 1,2 & 0,2107 & 0,0080 & 0,0305 & 0,0005 & 0,1932 & 32,8299 & 0,4958 & 0,0508 & 0,0021 & 193,3 & 6,7 & 193,4 & 2,9 & 193,4 & 2,9 \\
\hline VM1_21 & 253,0 & 0,9 & 0,2272 & 0,0075 & 0,0300 & 0,0004 & 0,4344 & 33,3333 & 0,4222 & 0,0550 & 0,0017 & 207,2 & 6,2 & 190,5 & 2,4 & 190,5 & 2,4 \\
\hline VM1_22 & 171,0 & 2,2 & 1,6830 & 0,0200 & 0,1696 & 0,0014 & 0,1652 & 5,8962 & 0,0487 & 0,0724 & 0,0010 & 1001,2 & 7,5 & 1009,5 & 8,0 & 988,0 & 27,0 \\
\hline VM1_23 & 529,0 & 2,6 & 3,7760 & 0,0550 & 0,2747 & 0,0030 & 0,7956 & 3,6403 & 0,0398 & 0,0985 & 0,0009 & 1586,0 & 11,0 & 1564,0 & 15,0 & 1593,0 & 17,0 \\
\hline VM1_24 & 319,0 & 3,9 & 0,5515 & 0,0080 & 0,0717 & 0,0007 & 0,0211 & 13,9528 & 0,1324 & 0,0559 & 0,0009 & 445,5 & 5,2 & 447,2 & 3,9 & 447,2 & 3,9 \\
\hline VM1_25 & 359,0 & 0,5 & 0,2082 & 0,0059 & 0,0302 & 0,0003 & 0,2550 & 33,0907 & 0,3504 & 0,0502 & 0,0014 & 191,6 & 4,9 & 191,9 & 2,0 & 191,9 & 2,0 \\
\hline VM1_26 & 188,0 & 1,8 & 0,3170 & 0,0120 & 0,0448 & 0,0006 & 0,2989 & 22,3015 & 0,3034 & 0,0514 & 0,0018 & 278,2 & 8,9 & 282,7 & 3,8 & 282,7 & 3,8 \\
\hline VM-1_1 & 272,9 & 1,3 & 1,5780 & 0,0290 & 0,1589 & 0,0018 & 0,3857 & 6,2933 & 0,0713 & 0,0715 & 0,0012 & 961,0 & 11,0 & 950,3 & 9,8 & 965,0 & 36,0 \\
\hline VM-1_2 & 561,0 & 2,2 & 1,5240 & 0,0240 & 0,1541 & 0,0027 & 0,5210 & 6,4893 & 0,1137 & 0,0713 & 0,0011 & 940,0 & 10,0 & 924,0 & 15,0 & 961,0 & 30,0 \\
\hline VM-1_3 & 37,9 & 1,2 & 0,2220 & 0,0280 & 0,0282 & 0,0008 & 0,2266 & 35,4988 & 0,9829 & 0,0567 & 0,0069 & 195,0 & 24,0 & 179,0 & 4,9 & 179,0 & 4,9 \\
\hline
\end{tabular}


Continuación Anexo 3.

\begin{tabular}{|c|c|c|c|c|c|c|c|c|c|c|c|c|c|c|c|c|c|}
\hline $\begin{array}{l}\text { Puntos de } \\
\text { análisis }\end{array}$ & $\begin{array}{c}\mathrm{U} \\
(\mathrm{ppm})\end{array}$ & $\mathrm{U} / \mathrm{Th}$ & ${ }^{207} \mathrm{~Pb} /{ }^{235} \mathrm{U}$ & $\pm 2 \sigma$ & ${ }^{206} \mathrm{~Pb} /{ }^{238} \mathrm{U}$ & $\pm 2 \sigma$ & $\begin{array}{l}\text { Coeficiente } \\
\text { Correlación }\end{array}$ & ${ }^{238} \mathrm{U} /{ }^{206} \mathrm{~Pb}$ & $\pm 2 \sigma$ & ${ }^{207} \mathrm{~Pb} /{ }^{206} \mathrm{~Pb}$ & $\pm 2 \sigma$ & $\begin{array}{c}{ }^{207} \mathrm{~Pb} /{ }^{235} \mathrm{U} \\
\mathrm{Ma}\end{array}$ & $\begin{array}{l} \pm 2 \sigma \\
\mathrm{Ma}\end{array}$ & $\begin{array}{c}{ }^{206} \mathrm{~Pb} /{ }^{238} \mathrm{U} \\
\mathrm{Ma}\end{array}$ & $\begin{array}{l} \pm 2 \sigma \\
\mathrm{Ma}\end{array}$ & $\begin{array}{c}\text { Best } \\
\text { Age } \\
\text { Ma }\end{array}$ & $\begin{array}{c}2 \sigma \\
\text { Abs } \\
\text { Error } \\
\text { Ma }\end{array}$ \\
\hline VM-1_4 & 92,5 & 0,9 & 1,6390 & 0,0440 & 0,1600 & 0,0034 & 0,2904 & 6,2500 & 0,1328 & 0,0738 & 0,0021 & 982,0 & 17,0 & 959,0 & 20,0 & 1011,0 & 58,0 \\
\hline VM-1_5 & 48,9 & 0,5 & 0,3850 & 0,0420 & 0,0387 & 0,0021 & 0,0001 & 25,8398 & 1,4022 & 0,0760 & 0,0100 & 327,0 & 31,0 & 245,0 & 13,0 & 245,0 & 13,0 \\
\hline VM-1_6 & 436,0 & 2,2 & 1,9280 & 0,0290 & 0,1811 & 0,0024 & 0,6414 & 5,5218 & 0,0732 & 0,0773 & 0,0009 & 1089,0 & 10,0 & 1074,0 & 13,0 & 1125,0 & 23,0 \\
\hline VM-1_7 & 313,8 & 8,5 & 1,7560 & 0,0340 & 0,1733 & 0,0024 & 0,5468 & 5,7703 & 0,0799 & 0,0727 & 0,0011 & 1028,0 & 12,0 & 1030,0 & 13,0 & 1005,0 & 32,0 \\
\hline VM-1_8 & 68,4 & 1,7 & 0,2040 & 0,0150 & 0,0287 & 0,0007 & 0,2256 & 34,7947 & 0,8596 & 0,0507 & 0,0039 & 186,0 & 13,0 & 183,2 & 4,6 & 183,2 & 4,6 \\
\hline VM-1_9 & 187,0 & 1,4 & 1,7760 & 0,0350 & 0,1705 & 0,0032 & 0,4304 & 5,8651 & 0,1101 & 0,0751 & 0,0016 & 1035,0 & 13,0 & 1014,0 & 18,0 & 1061,0 & 42,0 \\
\hline VM-1_10 & 38,6 & 1,4 & 0,1990 & 0,0220 & 0,0286 & 0,0009 & 0,0001 & 34,9895 & 1,0774 & 0,0525 & 0,0061 & 183,0 & 20,0 & 181,6 & 5,5 & 181,6 & 5,5 \\
\hline VM-1_11 & 1780,0 & 20,2 & 1,5710 & 0,0430 & 0,1585 & 0,0040 & 0,7725 & 6,3091 & 0,1592 & 0,0715 & 0,0013 & 957,0 & 17,0 & 948,0 & 23,0 & 964,0 & 35,0 \\
\hline VM-1_12 & 37,3 & 0,9 & 0,3120 & 0,0280 & 0,0308 & 0,0009 & 0,0336 & 32,5203 & 0,9835 & 0,0751 & 0,0070 & 268,0 & 22,0 & 195,2 & 5,8 & 195,2 & 5,8 \\
\hline VM-1_13 & 262,0 & 3,0 & 2,5030 & 0,0430 & 0,2147 & 0,0030 & 0,5904 & 4,6577 & 0,0651 & 0,0841 & 0,0012 & 1273,0 & 13,0 & 1256,0 & 15,0 & 1290,0 & 29,0 \\
\hline VM-1_14 & 179,1 & 10,7 & 1,6390 & 0,0270 & 0,1660 & 0,0026 & 0,4970 & 6,0241 & 0,0944 & 0,0712 & 0,0012 & 984,0 & 10,0 & 990,0 & 14,0 & 953,0 & 33,0 \\
\hline VM-1_15 & 459,0 & 6,3 & 1,6270 & 0,0240 & 0,1626 & 0,0021 & 0,5989 & 6,1501 & 0,0794 & 0,0721 & 0,0009 & 979,3 & 9,2 & 971,0 & 11,0 & 986,0 & 26,0 \\
\hline VM-1_16 & 17,7 & 2,0 & 0,2660 & 0,0680 & 0,0303 & 0,0019 & 0,0853 & 33,0033 & 2,0695 & 0,0640 & 0,0170 & 210,0 & 58,0 & 192,0 & 12,0 & 192,0 & 12,0 \\
\hline VM-1_17 & 62,3 & 5,6 & 1,6360 & 0,0420 & 0,1634 & 0,0028 & 0,2947 & 6,1200 & 0,1049 & 0,0720 & 0,0019 & 980,0 & 16,0 & 975,0 & 16,0 & 966,0 & 55,0 \\
\hline VM-1_18 & 238,0 & 6,1 & 3,0500 & 0,1200 & 0,2457 & 0,0079 & דוסלס, & 4,0700 & 0,1309 & 0,0895 & 0,0016 & 1404,0 & 32,0 & 1412,0 & 41,0 & 1412,0 & 33,0 \\
\hline VM-1_19 & 517,0 & 5,2 & 1,3080 & 0,0220 & 0,1291 & 0,0017 & 0,4835 & 7,7459 & 0,1020 & 0,0729 & 0,0011 & 849,1 & 9,4 & 782,3 & 9,5 & 782,3 & 9,5 \\
\hline VM-1_20 & 35,5 & 1,4 & 0,2080 & 0,0240 & 0,0287 & 0,0010 & 0,2650 & 34,8797 & 1,1801 & 0,0517 & 0,0059 & 189,0 & 20,0 & 182,2 & 6,1 & 182,2 & 6,1 \\
\hline VM-1_21 & 49,3 & 1,6 & 0,2140 & 0,0220 & 0,0281 & 0,0009 & 0,0001 & 35,5619 & 1,0876 & 0,0560 & 0,0063 & 193,0 & 19,0 & 178,7 & 5,4 & 178,7 & 5,4 \\
\hline VM-1_22 & 41,2 & 1,0 & 0,2610 & 0,0290 & 0,0285 & 0,0008 & 0,0001 & 35,0631 & 0,9958 & 0,0675 & 0,0080 & 229,0 & 24,0 & 181,2 & 5,1 & 181,2 & 5,1 \\
\hline VM-1_23 & 70,3 & 1,4 & 1,6000 & 0,0370 & 0,1552 & 0,0021 & 0,3609 & 6,4433 & 0,0872 & 0,0744 & 0,0016 & 968,0 & 14,0 & 930,0 & 12,0 & 1033,0 & 44,0 \\
\hline VM-1_24 & 134,0 & 2,1 & 1,6240 & 0,0390 & 0,1614 & 0,0029 & 0,5021 & 6,1958 & 0,1113 & 0,0726 & 0,0015 & 977,0 & 15,0 & 964,0 & 16,0 & 993,0 & 45,0 \\
\hline VM-1_25 & 228,8 & 4,1 & 1,7680 & 0,0290 & 0,1730 & 0,0028 & 0,5448 & 5,7803 & 0,0936 & 0,0743 & 0,0011 & 1035,0 & 11,0 & 1028,0 & 15,0 & 1039,0 & 31,0 \\
\hline VM-1_26 & 80,2 & 2,0 & 1,5420 & 0,0350 & 0,1581 & 0,0028 & 0,3663 & 6,3251 & 0,1120 & 0,0708 & 0,0016 & 944,0 & 14,0 & 945,0 & 16,0 & 926,0 & 46,0 \\
\hline VM-1_27 & 27,2 & 6,5 & 1,6870 & 0,0590 & 0,1685 & 0,0036 & 0,1692 & 5,9347 & 0,1268 & 0,0723 & 0,0026 & 999,0 & 22,0 & 1003,0 & 20,0 & 965,0 & 77,0 \\
\hline VM-1_28 & 63,8 & 1,1 & 0,2600 & 0,0220 & 0,0293 & 0,0008 & 0,4127 & 34,1647 & 0,9805 & 0,0641 & 0,0052 & 229,0 & 18,0 & 185,9 & 5,3 & 185,9 & 5,3 \\
\hline VM-1_29 & 19,3 & 7,4 & 1,3400 & 0,0670 & 0,1374 & 0,0029 & 0,0611 & 7,2780 & 0,1536 & 0,0720 & 0,0039 & 859,0 & 29,0 & 829,0 & 16,0 & 829,0 & 16,0 \\
\hline VM-1_30 & 107,9 & 3,3 & 1,6290 & 0,0320 & 0,1622 & 0,0027 & 0,2937 & 6,1652 & 0,1026 & 0,0726 & 0,0016 & 979,0 & 12,0 & 969,0 & 15,0 & 979,0 & 46,0 \\
\hline VM-1_31 & 1360,0 & 7,7 & 1,6870 & 0,0440 & 0,1641 & 0,0039 & 0,7434 & 6,0938 & 0,1448 & 0,0752 & 0,0013 & 1001,0 & 17,0 & 979,0 & 22,0 & 1073,0 & 36,0 \\
\hline VM-1_32 & 458,9 & 3,3 & 2,0340 & 0,0470 & 0,1876 & 0,0038 & 0,7947 & 5,3305 & 0,1080 & 0,0780 & 0,0011 & 1124,0 & 16,0 & 1108,0 & 21,0 & 1143,0 & 28,0 \\
\hline VM-1_33 & 1123,0 & 2,7 & 1,6290 & 0,0210 & 0,1619 & 0,0023 & 0,4833 & 6,1767 & 0,0877 & 0,0727 & 0,0011 & 980,5 & 7,9 & 967,0 & 13,0 & 997,0 & 30,0 \\
\hline VM-1_34 & 40,5 & 0,6 & 0,5570 & 0,0370 & 0,0553 & 0,0016 & 0,2377 & 18,0832 & 0,5232 & 0,0715 & 0,0053 & 445,0 & 24,0 & 347,0 & 10,0 & 347,0 & 10,0 \\
\hline
\end{tabular}




\begin{tabular}{|c|c|c|c|c|c|c|c|c|c|c|c|c|c|c|c|c|c|}
\hline $\begin{array}{l}\text { Puntos de } \\
\text { análisis }\end{array}$ & $\begin{array}{c}\mathrm{U} \\
(\mathrm{ppm})\end{array}$ & $\mathrm{U} / \mathrm{Th}$ & ${ }^{207} \mathrm{~Pb} /{ }^{235} \mathrm{U}$ & $\pm 2 \sigma$ & ${ }^{206} \mathrm{~Pb} /{ }^{238} \mathrm{U}$ & $\pm 2 \sigma$ & $\begin{array}{l}\text { Coeficiente } \\
\text { Correlación }\end{array}$ & ${ }^{238} \mathrm{U} /{ }^{206} \mathrm{~Pb}$ & $\pm 2 \sigma$ & ${ }^{207} \mathrm{~Pb} /{ }^{206} \mathrm{~Pb}$ & $\pm 2 \sigma$ & $\begin{array}{c}{ }^{207} \mathrm{~Pb} /{ }^{235} \mathrm{U} \\
\mathrm{Ma}\end{array}$ & $\begin{array}{l} \pm 2 \sigma \\
\mathrm{Ma}\end{array}$ & $\begin{array}{c}{ }^{206} \mathrm{~Pb} /{ }^{238} \mathrm{U} \\
\mathrm{Ma}\end{array}$ & $\begin{array}{l} \pm 2 \sigma \\
\mathrm{Ma}\end{array}$ & $\begin{array}{l}\text { Best } \\
\text { Age } \\
\text { Ma }\end{array}$ & $\begin{array}{c}2 \sigma \\
\text { Abs } \\
\text { Error } \\
\text { Ma }\end{array}$ \\
\hline VM-1_35 & 471,0 & 2,2 & 2,3440 & 0,0280 & 0,2055 & 0,0018 & 0,5456 & 4,8662 & 0,0426 & 0,0820 & 0,0009 & 1225,0 & 8,6 & 1204,6 & 9,5 & 1241,0 & 20,0 \\
\hline VM-1_36 & 1306,0 & 24,1 & 1,8630 & 0,0250 & 0,1773 & 0,0022 & 0,6388 & 5,6402 & 0,0700 & 0,0757 & 0,0009 & 1068,7 & 8,4 & 1052,0 & 12,0 & 1082,0 & 23,0 \\
\hline VM-1_37 & 194,0 & 7,2 & 1,6010 & 0,0400 & 0,1601 & 0,0039 & 0,6494 & 6,2461 & 0,1522 & 0,0734 & 0,0015 & 968,0 & 15,0 & 956,0 & 21,0 & 1020,0 & 39,0 \\
\hline VM-1_39 & 85,2 & 1,2 & 0,2320 & 0,0160 & 0,0280 & 0,0006 & 0,0131 & 35,7143 & 0,8163 & 0,0613 & 0,0045 & 211,0 & 13,0 & 178,0 & 4,0 & 178,0 & 4,0 \\
\hline VM-1_40 & 1160,0 & 18,0 & 1,5460 & 0,0280 & 0,1481 & 0,0025 & 0,5724 & 6,7522 & 0,1140 & 0,0765 & 0,0013 & 949,0 & 12,0 & 890,0 & 14,0 & 1099,0 & 34,0 \\
\hline VM-1_41 & 719,0 & 10,3 & 1,5590 & 0,0290 & 0,1514 & 0,0025 & 0,6683 & 6,6050 & 0,1091 & 0,0752 & 0,0012 & 952,0 & 11,0 & 909,0 & 14,0 & 1067,0 & 31,0 \\
\hline VM-1_42 & 927,0 & 6,2 & 1,6530 & 0,0170 & 0,1624 & 0,0013 & 0,6787 & 6,1576 & 0,0493 & 0,0731 & 0,0007 & 990,4 & 6,4 & 970,1 & 7,2 & 1012,0 & 19,0 \\
\hline VM-1_43 & 43,7 & 5,7 & 1,6950 & 0,0510 & 0,1709 & 0,0027 & 0,3488 & 5,8514 & 0,0924 & 0,0715 & 0,0020 & 1001,0 & 19,0 & 1017,0 & 15,0 & 946,0 & 58,0 \\
\hline VM-1_44 & 21,7 & 2,6 & 1,7120 & 0,0760 & 0,1683 & 0,0036 & 0,2657 & 5,9418 & 0,1271 & 0,0734 & 0,0034 & 1004,0 & 28,0 & 1002,0 & 20,0 & 958,0 & 94,0 \\
\hline VM-1_45 & 436,0 & 6,4 & 1,5230 & 0,0320 & 0,1556 & 0,0028 & 0,6058 & 6,4267 & 0,1156 & 0,0714 & 0,0012 & 938,0 & 13,0 & 932,0 & 16,0 & 956,0 & 34,0 \\
\hline VM-1_46 & 52,0 & 14,5 & 1,6570 & 0,0440 & 0,1688 & 0,0029 & 0,3889 & 5,9242 & 0,1018 & 0,0713 & 0,0019 & 990,0 & 17,0 & 1005,0 & 16,0 & 934,0 & 57,0 \\
\hline VM-1_47 & 381,0 & 8,9 & 2,0040 & 0,0500 & 0,1839 & 0,0041 & 0,8191 & 5,4377 & 0,1212 & 0,0783 & 0,0012 & 1114,0 & 17,0 & 1087,0 & 22,0 & 1154,0 & 28,0 \\
\hline VM-1_48 & 880,0 & 11,8 & 1,5470 & 0,0270 & 0,1505 & 0,0029 & 0,5856 & 6,6445 & 0,1280 & 0,0754 & 0,0012 & 951,0 & 11,0 & 903,0 & 16,0 & 1074,0 & 34,0 \\
\hline VM-1_49 & 670,0 & 4,4 & 2,2320 & 0,0640 & 0,2059 & 0,0082 & 0,6100 & 4,8567 & 0,1934 & 0,0811 & 0,0027 & 1189,0 & 20,0 & 1205,0 & 44,0 & 1209,0 & 65,0 \\
\hline VM-1_50 & 179,8 & 2,1 & 1,5770 & 0,0280 & 0,1582 & 0,0022 & 0,3902 & 6,3211 & 0,0879 & 0,0723 & 0,0011 & 959,0 & 11,0 & 946,0 & 12,0 & 984,0 & 33,0 \\
\hline VM-1_51 & 680,0 & 7,8 & 1,7840 & 0,0220 & 0,1739 & 0,0019 & 0,5170 & 5,7504 & 0,0628 & 0,0743 & 0,0009 & 1038,3 & 8,1 & 1033,0 & 10,0 & 1045,0 & 23,0 \\
\hline VM-1_52 & 409,0 & 1,1 & 1,4370 & 0,0290 & 0,1422 & 0,0026 & 0,3398 & 7,0323 & 0,1286 & 0,0730 & 0,0017 & 902,0 & 12,0 & 857,0 & 15,0 & 996,0 & 47,0 \\
\hline VM-1_53 & 79,5 & 3,0 & 1,6540 & 0,0310 & 0,1643 & 0,0018 & 0,2284 & 6,0864 & 0,0667 & 0,0729 & 0,0013 & 989,0 & 12,0 & 980,5 & 9,7 & 998,0 & 38,0 \\
\hline VM-1_54 & 144,4 & 12,8 & 1,6110 & 0,0300 & 0,1593 & 0,0020 & 0,3100 & 6,2775 & 0,0788 & 0,0730 & 0,0014 & 973,0 & 12,0 & 953,0 & 11,0 & 1000,0 & 39,0 \\
\hline VM-1_55 & 15,4 & 3,1 & 1,6970 & 0,0810 & 0,1710 & 0,0039 & 0,3637 & 5,8480 & 0,1334 & 0,0713 & 0,0033 & 1005,0 & 29,0 & 1017,0 & 22,0 & 907,0 & 99,0 \\
\hline VM-1_56 & 85,0 & 1,6 & 0,2170 & 0,0310 & 0,0304 & 0,0014 & 0,0001 & 32,8947 & 1,5149 & 0,0547 & 0,0083 & 195,0 & 26,0 & 193,3 & 8,8 & 193,3 & 8,8 \\
\hline VM-1_57 & 523,0 & 5,6 & 2,1830 & 0,0270 & 0,1983 & 0,0024 & 0,5973 & 5,0429 & 0,0610 & 0,0802 & 0,0009 & 1176,7 & 9,0 & 1166,0 & 13,0 & 1195,0 & 23,0 \\
\hline VM-1_58 & 129,6 & 0,8 & 1,6140 & 0,0270 & 0,1577 & 0,0017 & 0,0001 & 6,3412 & 0,0684 & 0,0736 & 0,0014 & 974,0 & 10,0 & 943,5 & 9,4 & 1016,0 & 39,0 \\
\hline VM-1_60 & 423,0 & 1,7 & 1,4400 & 0,0270 & 0,1489 & 0,0025 & 0,5976 & 6,7159 & 0,1128 & 0,0706 & 0,0011 & 904,0 & 11,0 & 894,0 & 14,0 & 938,0 & 32,0 \\
\hline VM-1_61 & 84,0 & 1,3 & 0,2400 & 0,0240 & 0,0301 & 0,0008 & 0,1377 & 33,2226 & 0,8388 & 0,0583 & 0,0058 & 214,0 & 19,0 & 191,1 & 4,7 & 191,1 & 4,7 \\
\hline VM-1_62 & 38,5 & 1,3 & 0,2420 & 0,0300 & 0,0283 & 0,0008 & 0,3077 & 35,3482 & 0,9871 & 0,0610 & 0,0077 & 212,0 & 25,0 & 179,8 & 4,9 & 179,8 & 4,9 \\
\hline VM-1_63 & 173,7 & 1,0 & 0,2990 & 0,0290 & 0,0298 & 0,0010 & 0,0304 & 33,6022 & 1,1178 & 0,0754 & 0,0077 & 263,0 & 22,0 & 189,0 & 6,2 & 189,0 & 6,2 \\
\hline VM-1_64 & 334,3 & 3,8 & 2,2570 & 0,0460 & 0,1965 & 0,0028 & 0,6448 & 5,0891 & 0,0725 & 0,0826 & 0,0013 & 1197,0 & 15,0 & 1159,0 & 14,0 & 1260,0 & 30,0 \\
\hline VM-1_65 & 40,1 & 1,3 & 0,3150 & 0,0240 & 0,0303 & 0,0007 & 0,1495 & 33,0469 & 0,7208 & 0,0761 & 0,0061 & 272,0 & 19,0 & 192,1 & 4,1 & 192,1 & 4,1 \\
\hline VM-1_66 & 623,0 & 3,3 & 2,6980 & 0,0360 & 0,2198 & 0,0028 & 0,6896 & 4,5496 & 0,0580 & 0,0883 & 0,0009 & 1326,8 & 9,9 & 1281,0 & 15,0 & 1388,0 & 19,0 \\
\hline VM-1_67 & 75,7 & 3,6 & 1,6500 & 0,0400 & 0,1621 & 0,0021 & 0,1943 & 6,1690 & 0,0799 & 0,0734 & 0,0018 & 987,0 & 15,0 & 968,0 & 12,0 & 1011,0 & 49,0 \\
\hline
\end{tabular}




\begin{tabular}{|c|c|c|c|c|c|c|c|c|c|c|c|c|c|c|c|c|c|}
\hline $\begin{array}{l}\text { Puntos de } \\
\text { análisis }\end{array}$ & $\begin{array}{c}\mathrm{U} \\
(\mathrm{ppm})\end{array}$ & $\mathrm{U} / \mathrm{Th}$ & ${ }^{207} \mathrm{~Pb} /{ }^{235} \mathrm{U}$ & $\pm 2 \sigma$ & ${ }^{206} \mathrm{~Pb} /{ }^{238} \mathrm{U}$ & $\pm 2 \sigma$ & $\begin{array}{l}\text { Coeficiente } \\
\text { Correlación }\end{array}$ & ${ }^{238} \mathrm{U} /{ }^{206} \mathrm{~Pb}$ & $\pm 2 \sigma$ & ${ }^{207} \mathrm{~Pb} /{ }^{206} \mathrm{~Pb}$ & $\pm 2 \sigma$ & $\begin{array}{c}{ }^{207} \mathrm{~Pb} /{ }^{235} \mathrm{U} \\
\mathrm{Ma}\end{array}$ & $\begin{array}{l} \pm 2 \sigma \\
\mathrm{Ma}\end{array}$ & $\begin{array}{c}{ }^{206} \mathrm{~Pb} /{ }^{238} \mathrm{U} \\
\mathrm{Ma}\end{array}$ & $\begin{array}{l} \pm 2 \sigma \\
\mathrm{Ma}\end{array}$ & $\begin{array}{c}\text { Best } \\
\text { Age } \\
\text { Ma }\end{array}$ & $\begin{array}{c}2 \sigma \\
\text { Abs } \\
\text { Error } \\
\text { Ma }\end{array}$ \\
\hline VM-1_68 & 93,4 & 7,9 & 1,6400 & 0,0340 & 0,1648 & 0,0022 & 0,2941 & 6,0680 & 0,0810 & 0,0718 & 0,0015 & 983,0 & 13,0 & 985,0 & 13,0 & 965,0 & 44,0 \\
\hline VM-1_70 & 141,4 & 2,5 & 2,3800 & 0,0440 & 0,2061 & 0,0033 & 0,4512 & 4,8520 & 0,0777 & 0,0830 & 0,0014 & 1235,0 & 13,0 & 1210,0 & 17,0 & 1264,0 & 36,0 \\
\hline VM-1_71 & 75,9 & 1,0 & 0,2240 & 0,0180 & 0,0291 & 0,0007 & 0,0049 & 34,4234 & 0,8650 & 0,0556 & 0,0046 & 203,0 & 15,0 & 184,6 & 4,6 & 184,6 & 4,6 \\
\hline VM-1_72 & 232,0 & 1,9 & 1,5070 & 0,0280 & 0,1538 & 0,0027 & 0,5204 & 6,5020 & 0,1141 & 0,0709 & 0,0012 & 931,0 & 11,0 & 922,0 & 15,0 & 943,0 & 35,0 \\
\hline VM-1_73 & 306,0 & 0,9 & 0,1975 & 0,0058 & 0,0281 & 0,0004 & 0,3816 & 35,6506 & 0,5338 & 0,0516 & 0,0016 & 182,6 & 4,9 & 178,3 & 2,6 & 178,3 & 2,6 \\
\hline VM-1_74 & 534,0 & 4,7 & 1,9730 & 0,0330 & 0,1853 & 0,0030 & 0,4929 & 5,3967 & 0,0874 & 0,0774 & 0,0013 & 1105,0 & 11,0 & 1095,0 & 16,0 & 1128,0 & 33,0 \\
\hline VM-1_75 & 443,0 & 6,1 & 2,4970 & 0,0330 & 0,2134 & 0,0026 & 0,6218 & 4,6860 & 0,0571 & 0,0844 & 0,0010 & 1271,6 & 9,9 & 1247,0 & 14,0 & 1296,0 & 23,0 \\
\hline VM-1_76 & 271,9 & 3,2 & 2,1480 & 0,0300 & 0,1970 & 0,0025 & 0,5941 & 5,0761 & 0,0644 & 0,0786 & 0,0010 & 1162,9 & 9,7 & 1159,0 & 13,0 & 1155,0 & 24,0 \\
\hline VM-1_77 & 62,5 & 5,7 & 1,7020 & 0,0460 & 0,1693 & 0,0027 & 0,2704 & 5,9067 & 0,0942 & 0,0726 & 0,0019 & 1005,0 & 17,0 & 1008,0 & 15,0 & 977,0 & 55,0 \\
\hline VM-1_78 & 113,6 & 1,3 & 0,1830 & 0,0120 & 0,0280 & 0,0006 & 0,0148 & 35,6633 & 0,7504 & 0,0481 & 0,0031 & 169,4 & 9,9 & 178,3 & 3,7 & 178,3 & 3,7 \\
\hline VM-1_79 & 183,9 & 1,3 & 1,6040 & 0,0340 & 0,1611 & 0,0037 & 0,4641 & 6,2073 & 0,1426 & 0,0728 & 0,0016 & 972,0 & 14,0 & 962,0 & 20,0 & 1000,0 & 47,0 \\
\hline VM-1_80 & 182,8 & 2,1 & 1,5330 & 0,0290 & 0,1525 & 0,0028 & 0,4916 & 6,5574 & 0,1204 & 0,0726 & 0,0015 & 942,0 & 12,0 & 914,0 & 16,0 & 985,0 & 42,0 \\
\hline VM-1_81 & 676,0 & 4,6 & 4,3480 & 0,0890 & 0,3051 & 0,0064 & 0,6019 & 3,2776 & 0,0688 & 0,1043 & 0,0017 & 1703,0 & 16,0 & 1715,0 & 32,0 & 1700,0 & 32,0 \\
\hline VM-1_82 & 10,5 & 3,0 & 1,0900 & 0,1300 & 0,1180 & 0,0074 & 0,3733 & 8,4746 & 0,5315 & 0,0691 & 0,0075 & 715,0 & 64,0 & 716,0 & 42,0 & 716,0 & 42,0 \\
\hline VM-1_83 & 210,1 & 2,1 & 2,3950 & 0,0410 & 0,2070 & 0,0032 & 0,6642 & 4,8309 & 0,0747 & 0,0834 & 0,0012 & 1241,0 & 13,0 & 1212,0 & 17,0 & 1272,0 & 28,0 \\
\hline VM-1_84 & 29,9 & 1,7 & 0,2190 & 0,0260 & 0,0295 & 0,0009 & 0,1530 & 33,8983 & 1,0572 & 0,0539 & 0,0068 & 191,0 & 23,0 & 187,3 & 5,7 & 187,3 & 5,7 \\
\hline VM-1_85 & 962,0 & 2,9 & 1,5390 & 0,0250 & 0,1532 & 0,0021 & 0,6209 & 6,5274 & 0,0895 & 0,0723 & 0,0009 & 945,0 & 10,0 & 919,0 & 12,0 & 992,0 & 25,0 \\
\hline VM-1_86 & 47,5 & 1,9 & 0,2010 & 0,0180 & 0,0280 & 0,0007 & 0,0001 & 35,6633 & 0,8776 & 0,0536 & 0,0052 & 182,0 & 15,0 & 178,2 & 4,3 & 178,2 & 4,3 \\
\hline VM-1_87 & 381,0 & 1,8 & 1,3640 & 0,0550 & 0,1380 & 0,0050 & 0,9058 & 7,2464 & 0,2625 & 0,0711 & 0,0013 & 870,0 & 24,0 & 832,0 & 28,0 & 832,0 & 28,0 \\
\hline VM-1_88 & 136,2 & 1,5 & 1,6030 & 0,0410 & 0,1590 & 0,0029 & 0,3321 & 6,2893 & 0,1147 & 0,0727 & 0,0019 & 969,0 & 16,0 & 951,0 & 16,0 & 987,0 & 53,0 \\
\hline VM-1_89 & 138,0 & 1,9 & 1,9120 & 0,0600 & 0,1818 & 0,0045 & 0,5610 & 5,5006 & 0,1362 & 0,0765 & 0,0018 & 1077,0 & 22,0 & 1078,0 & 24,0 & 1101,0 & 45,0 \\
\hline VM-1_90 & 32,3 & 1,6 & 0,2050 & 0,0350 & 0,0287 & 0,0011 & 0,3240 & 34,8432 & 1,3355 & 0,0505 & 0,0085 & 180,0 & 29,0 & 182,1 & 6,8 & 182,1 & 6,8 \\
\hline VM-1_91 & 183,0 & 1,4 & 1,6650 & 0,0480 & 0,1651 & 0,0041 & 0,5556 & 6,0569 & 0,1504 & 0,0735 & 0,0019 & 993,0 & 19,0 & 984,0 & 23,0 & 1005,0 & 54,0 \\
\hline VM-1_92 & 68,6 & 2,5 & 1,6430 & 0,0350 & 0,1644 & 0,0025 & 0,0864 & 6,0827 & 0,0925 & 0,0716 & 0,0018 & 985,0 & 13,0 & 981,0 & 14,0 & 954,0 & 53,0 \\
\hline VM-1_93 & 205,5 & 2,5 & 1,9570 & 0,0570 & 0,1852 & 0,0057 & 0,7662 & 5,3996 & 0,1662 & 0,0764 & 0,0016 & 1097,0 & 20,0 & 1094,0 & 31,0 & 1099,0 & 41,0 \\
\hline VM-1_95 & 391,0 & 0,7 & 1,6720 & 0,0230 & 0,1676 & 0,0023 & 0,4370 & 5,9666 & 0,0819 & 0,0725 & 0,0010 & 997,7 & 8,8 & 998,0 & 13,0 & 991,0 & 28,0 \\
\hline VM-1_97 & 147,1 & 3,6 & 1,9500 & 0,0430 & 0,1813 & 0,0032 & 0,3982 & 5,5157 & 0,0974 & 0,0780 & 0,0017 & 1095,0 & 15,0 & 1074,0 & 18,0 & 1129,0 & 44,0 \\
\hline VM-1_98 & 39,0 & 0,9 & 0,2200 & 0,0270 & 0,0307 & 0,0009 & 0,1865 & 32,5733 & 0,9655 & 0,0525 & 0,0062 & 198,0 & 23,0 & 194,9 & 5,7 & 194,9 & 5,7 \\
\hline VM-1_99 & 66,5 & 0,5 & 0,3830 & 0,0260 & 0,0404 & 0,0011 & 0,0159 & 24,7525 & 0,6740 & 0,0696 & 0,0049 & 326,0 & 19,0 & 255,0 & 6,9 & 255,0 & 6,9 \\
\hline VM-1_100 & 261,1 & 2,7 & 2,2260 & 0,0240 & 0,2032 & 0,0016 & 0,2811 & 4,9213 & 0,0388 & 0,0788 & 0,0009 & 1188,4 & 7,7 & 1192,4 & 8,4 & 1162,0 & 23,0 \\
\hline VM-1_101 & 81,6 & 1,2 & 0,1780 & 0,0120 & 0,0289 & 0,0006 & 0,1278 & 34,6500 & 0,7444 & 0,0466 & 0,0033 & 166,0 & 10,0 & 183,4 & 3,9 & 183,4 & 3,9 \\
\hline
\end{tabular}




\begin{tabular}{|c|c|c|c|c|c|c|c|c|c|c|c|c|c|c|c|c|c|}
\hline $\begin{array}{l}\text { Puntos de } \\
\text { análisis }\end{array}$ & $\begin{array}{c}\mathrm{U} \\
(\mathrm{ppm})\end{array}$ & $\mathrm{U} / \mathrm{Th}$ & ${ }^{207} \mathrm{~Pb} /{ }^{235} \mathrm{U}$ & $\pm 2 \sigma$ & ${ }^{206} \mathrm{~Pb} /{ }^{238} \mathrm{U}$ & $\pm 2 \sigma$ & $\begin{array}{l}\text { Coeficiente } \\
\text { Correlación }\end{array}$ & ${ }^{238} \mathrm{U} /{ }^{206} \mathrm{~Pb}$ & $\pm 2 \sigma$ & ${ }^{207} \mathrm{~Pb} /{ }^{206} \mathrm{~Pb}$ & $\pm 2 \sigma$ & $\begin{array}{c}{ }^{207} \mathrm{~Pb} /{ }^{235} \mathrm{U} \\
\mathrm{Ma}\end{array}$ & $\begin{array}{l} \pm 2 \sigma \\
\text { Ma }\end{array}$ & $\begin{array}{c}{ }^{206} \mathrm{~Pb} /{ }^{238} \mathrm{U} \\
\mathrm{Ma}\end{array}$ & $\begin{array}{l} \pm 2 \sigma \\
\text { Ma }\end{array}$ & $\begin{array}{c}\text { Best } \\
\text { Age } \\
\text { Ma }\end{array}$ & $\begin{array}{c}2 \sigma \\
\text { Abs } \\
\text { Error } \\
\text { Ma }\end{array}$ \\
\hline VM-1_103 & 110,0 & 0,9 & 0,2300 & 0,0110 & 0,0309 & 0,0005 & 0,0001 & 32,4149 & 0,5359 & 0,0549 & 0,0028 & 209,2 & 8,6 & 195,8 & 3,2 & 195,8 & 3,2 \\
\hline VM-1_104 & 156,0 & 1,1 & 0,2200 & 0,0110 & 0,0307 & 0,0005 & 0,1834 & 32,6158 & 0,4893 & 0,0518 & 0,0025 & 201,2 & 9,0 & 194,7 & 2,9 & 194,7 & 2,9 \\
\hline VM-1_105 & 702,0 & 3,0 & 1,7030 & 0,0160 & 0,1699 & 0,0017 & 0,5180 & 5,8858 & 0,0589 & 0,0726 & 0,0007 & 1009,1 & 5,9 & 1011,3 & 9,5 & 997,0 & 18,0 \\
\hline VM-1_106 & 149,5 & 1,0 & 3,4470 & 0,0390 & 0,2655 & 0,0022 & 0,4196 & 3,7665 & 0,0312 & 0,0935 & 0,0011 & 1514,1 & 9,0 & 1518,0 & 11,0 & 1493,0 & 22,0 \\
\hline VM-1_107 & 1361,0 & 1,9 & 0,5369 & 0,0063 & 0,0700 & 0,0006 & 0,6216 & 14,2959 & 0,1308 & 0,0559 & 0,0005 & 436,0 & 4,2 & 435,8 & 3,8 & 435,8 & 3,8 \\
\hline VM-1_108 & 365,0 & 1,7 & 1,4370 & 0,0390 & 0,1499 & 0,0040 & 0,8943 & 6,6711 & 0,1780 & 0,0697 & 0,0008 & 900,0 & 16,0 & 899,0 & 22,0 & 912,0 & 24,0 \\
\hline VM-1_109 & 270,0 & 2,3 & 1,9660 & 0,0220 & 0,1867 & 0,0014 & 0,3399 & 5,3562 & 0,0402 & 0,0764 & 0,0008 & 1103,0 & 7,3 & 1103,1 & 7,4 & 1100,0 & 21,0 \\
\hline VM-1_110 & 278,0 & 1,0 & 0,2145 & 0,0062 & 0,0297 & 0,0004 & 0,0971 & 33,6927 & 0,4087 & 0,0527 & 0,0016 & 197,7 & 5,0 & 188,5 & 2,2 & 188,5 & 2,2 \\
\hline VM-1_111 & 762,0 & 1,5 & 1,6700 & 0,0180 & 0,1666 & 0,0018 & 0,4452 & 6,0024 & 0,0649 & 0,0730 & 0,0008 & 996,7 & 6,7 & 993,0 & 10,0 & 1008,0 & 21,0 \\
\hline WM1_1 & 46,4 & 1,5 & 0,3462 & 0,0063 & 0,0482 & 0,0007 & 0,4129 & 20,7555 & 0,3145 & 0,0522 & 0,0010 & 301,4 & 4,8 & 303,3 & 4,5 & 303,3 & 4,5 \\
\hline WM1_2 & 90,0 & 4,6 & 2,1880 & 0,0410 & 0,2003 & 0,0033 & 0,5039 & 4,9925 & 0,0823 & 0,0794 & 0,0015 & 1175,0 & 13,0 & 1176,0 & 18,0 & 1175,0 & 37,0 \\
\hline WM1_3 & 110,8 & 1,8 & 1,7390 & 0,0450 & 0,1717 & 0,0034 & 0,3063 & 5,8241 & 0,1153 & 0,0734 & 0,0020 & 1021,0 & 17,0 & 1021,0 & 19,0 & 1012,0 & 59,0 \\
\hline WM1_4 & 108,8 & 1,5 & 0,3824 & 0,0065 & 0,0502 & 0,0004 & 0,1218 & 19,9322 & 0,1748 & 0,0547 & 0,0010 & 328,6 & 4,8 & 315,6 & 2,7 & 315,6 & 2,7 \\
\hline WM1_5 & 124,3 & 7,5 & 1,7960 & 0,0340 & 0,1738 & 0,0018 & 0,4862 & 5,7537 & 0,0596 & 0,0744 & 0,0012 & 1042,0 & 12,0 & 1033,0 & 10,0 & 1043,0 & 33,0 \\
\hline WM1_6 & 424,9 & 1,6 & 0,5660 & 0,0130 & 0,0729 & 0,0009 & 0,3447 & 13,7099 & 0,1710 & 0,0562 & 0,0012 & 454,4 & 8,1 & 453,8 & 5,5 & 453,8 & 5,5 \\
\hline WM1_7 & 134,1 & 1,4 & 2,8770 & 0,0410 & 0,2201 & 0,0033 & 0,3968 & 4,5434 & 0,0681 & 0,0943 & 0,0014 & 1375,0 & 11,0 & 1282,0 & 17,0 & 1509,0 & 27,0 \\
\hline WM1_8 & 305,6 & 1,1 & 0,4050 & 0,0100 & 0,0528 & 0,0008 & 0,1554 & 18,9538 & 0,2766 & 0,0555 & 0,0015 & 344,1 & 7,5 & 332,0 & 4,8 & 332,0 & 4,8 \\
\hline WM1_9 & 69,0 & 1,2 & 0,5750 & 0,0110 & 0,0739 & 0,0008 & 0,4184 & 13,5318 & 0,1428 & 0,0562 & 0,0010 & 460,5 & 6,8 & 459,6 & 4,7 & 459,6 & 4,7 \\
\hline WM1_10 & 101,2 & 10,2 & 0,6142 & 0,0091 & 0,0758 & 0,0010 & 0,3924 & 13,1926 & 0,1740 & 0,0586 & 0,0010 & 486,6 & 5,5 & 470,8 & 6,0 & 470,8 & 6,0 \\
\hline WM1_11 & 234,6 & 0,7 & 1,5600 & 0,0370 & 0,1609 & 0,0021 & 0,2403 & 6,2150 & 0,0811 & 0,0703 & 0,0017 & 953,0 & 15,0 & 961,0 & 12,0 & 923,0 & 49,0 \\
\hline WM1_12 & 239,8 & 1,8 & 1,5870 & 0,0510 & 0,1572 & 0,0041 & 0,8348 & 6,3613 & 0,1659 & 0,0730 & 0,0014 & 962,0 & 20,0 & 940,0 & 23,0 & 1005,0 & 39,0 \\
\hline WM1_13 & 33,8 & 1,5 & 0,7710 & 0,0110 & 0,0938 & 0,0009 & 0,2733 & 10,6655 & 0,1058 & 0,0597 & 0,0009 & 579,5 & 6,3 & 577,7 & 5,5 & 577,7 & 5,5 \\
\hline WM1_14 & 137,0 & 4,7 & 0,3889 & 0,0079 & 0,0481 & 0,0007 & 0,3299 & 20,7900 & 0,2809 & 0,0581 & 0,0012 & 333,2 & 5,8 & 303,5 & 4,1 & 303,5 & 4,1 \\
\hline WM1_15 & 317,6 & 10,2 & 1,2560 & 0,0240 & 0,1341 & 0,0019 & 0,5682 & 7,4571 & 0,1057 & 0,0679 & 0,0011 & 827,0 & 10,0 & 811,0 & 11,0 & 811,0 & 11,0 \\
\hline
\end{tabular}

